\title{
An American Conundrum: Race, Sociology, And The African American Road To Citizenship
}

\section{Citation}

Bobo, Lawrence D. 2012. An American Conundrum: Race, Sociology, And The African American Road To Citizenship. In The Oxford Handbook of African American Citizenship, 1865-Present, edited by Henry Louis Gates, Jr., Claude Steele, Lawrence D. Bobo, Michael c. Dawson, Gerald Jaynes, Lisa Crooms-Robinson, and Linda Darling-Hammond, 19-70. New York: Oxford University Press.

\section{Published Version}

doi:10.1093/oxfordhb/9780195188059.013.0002

\section{Permanent link}

http://nrs.harvard.edu/urn-3:HUL.InstRepos:32197880

\section{Terms of Use}

This article was downloaded from Harvard University's DASH repository, and is made available under the terms and conditions applicable to Other Posted Material, as set forth at http:// nrs.harvard.edu/urn-3:HUL.InstRepos:dash.current.terms-of-use\#LAA

\section{Share Your Story}

The Harvard community has made this article openly available.

Please share how this access benefits you. Submit a story.

Accessibility 
THE OXFORD HANDBOOK OF
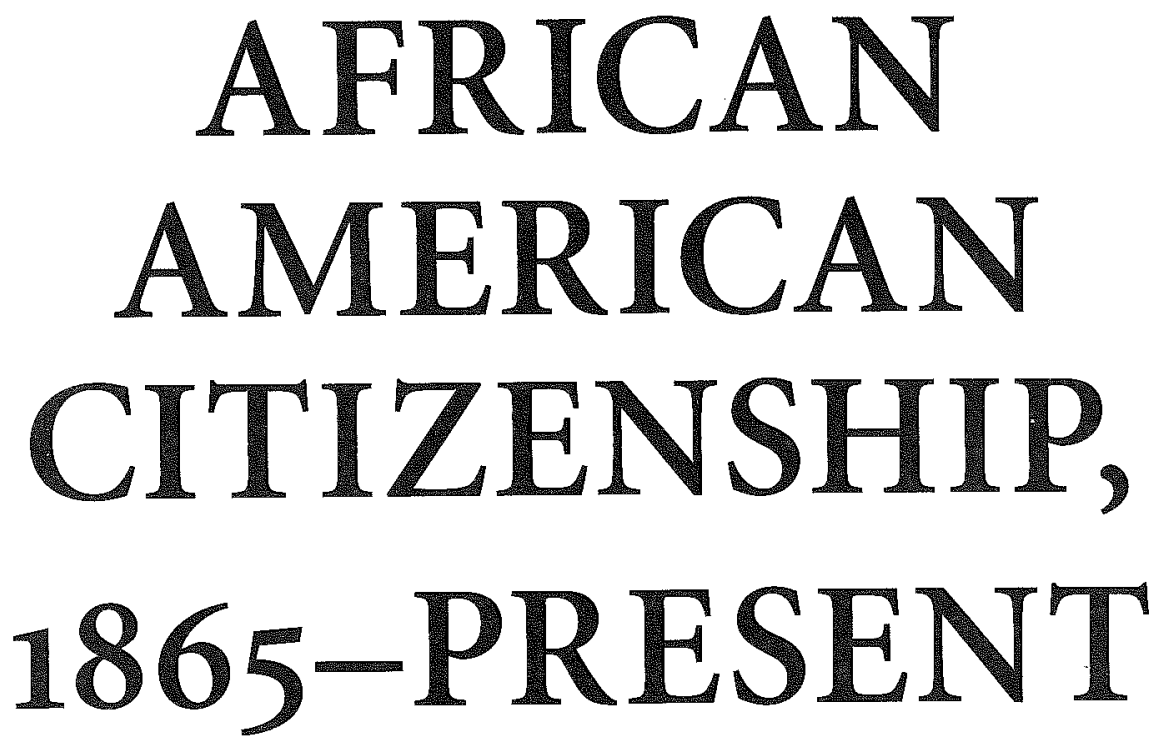

Edited by

HENRY LOUIS GATES, JR.

CLAUDE STEELE

LAWRENCE D. BOBO

MICHAEL C. DAWSON

GERALD JAYNES

LISA CROOMS-ROBINSON

LINDA DARLING-HAMMOND 


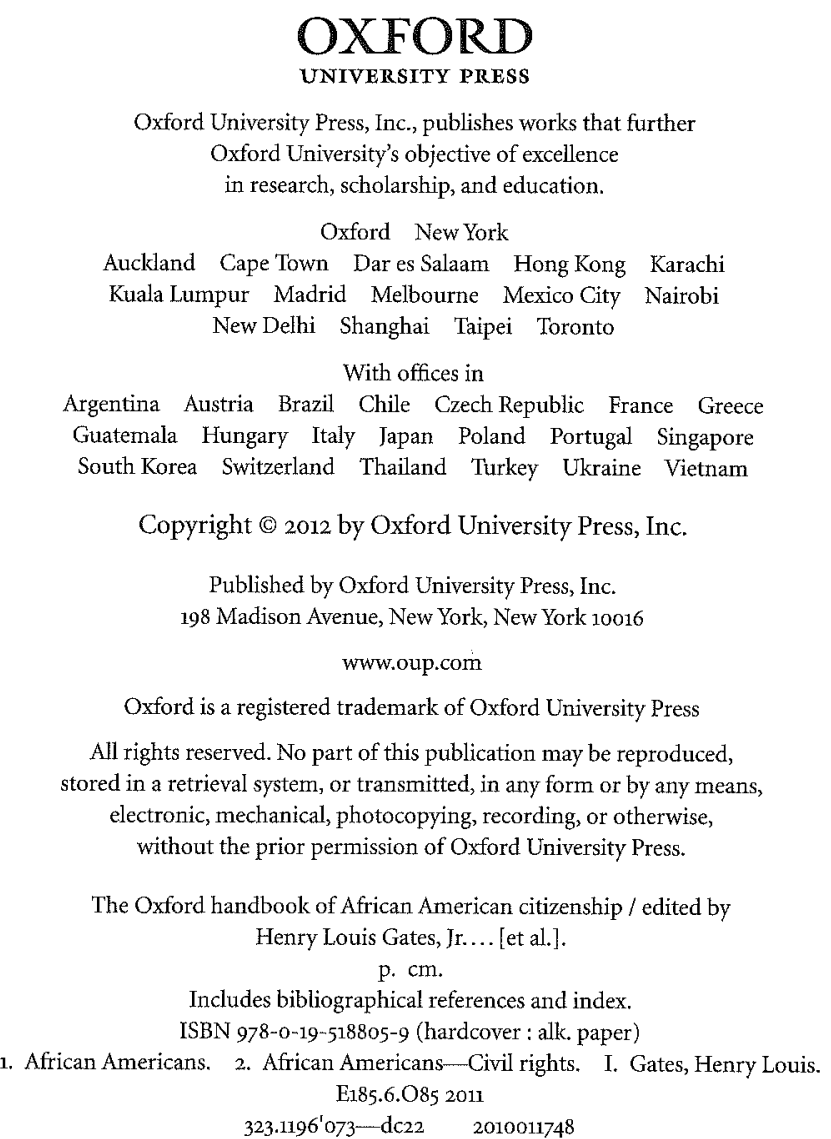

$$
\text { www.oup.com }
$$

Oxford is a registered trademark of Oxford University Press

All rights reserved. No part of this publication may be reproduced, stored in a retrieval system, or transmitted, in any form or by any means electronic, mechanical, photocopying, recording, or otherwise

without the prior permission of Oxford University Press.

The Oxford handbook of African American citizenship / edited by Henry Louis Gates, Jr... [et al.].

P. cm.

Includes bibliographical references and index.

African Americans. 2. African Americans-Civil rights. I. Gates, Henry Louis. E185.6.085 2011

$323.1196^{\prime} 073-\mathrm{dc22} \quad 2010011748$

\section{Contents}

List of Contributors ix

\section{INTRODUCTION}

1. African American Citizenship 3

Henry Louis Gates, Jr.

II. The African American Social Experience, 1865-Present

2. An American Conundrum: Race, Sociology, and the African American Road to Citizenship 19

Lawrence D. Bobo

3. Race and the Limits of American Democracy: African Americans from the Fall of Reconstruction to the Rise of the Ghetto 71

Frank L. Samson

4. The Strange Career of Racial Science, Racial Categories, and African American Identity 123

Victor Thompson

5. Race-Conscious Color Blindness: World War II, Brown v. Board of Education, and the Strange Persistence of the One-Drop Rule Victor Thompson

6. From Color Caste to Color Blind, Part I: Racial Attitudes in the United States during World War II, 1939-1945 178

Maria Krysan

7. From Color Caste to Color Blind, Part II: Racial Attitudes during the Civil Rights and Black Power Eras, 1946-1975 195 Maria Krysan 


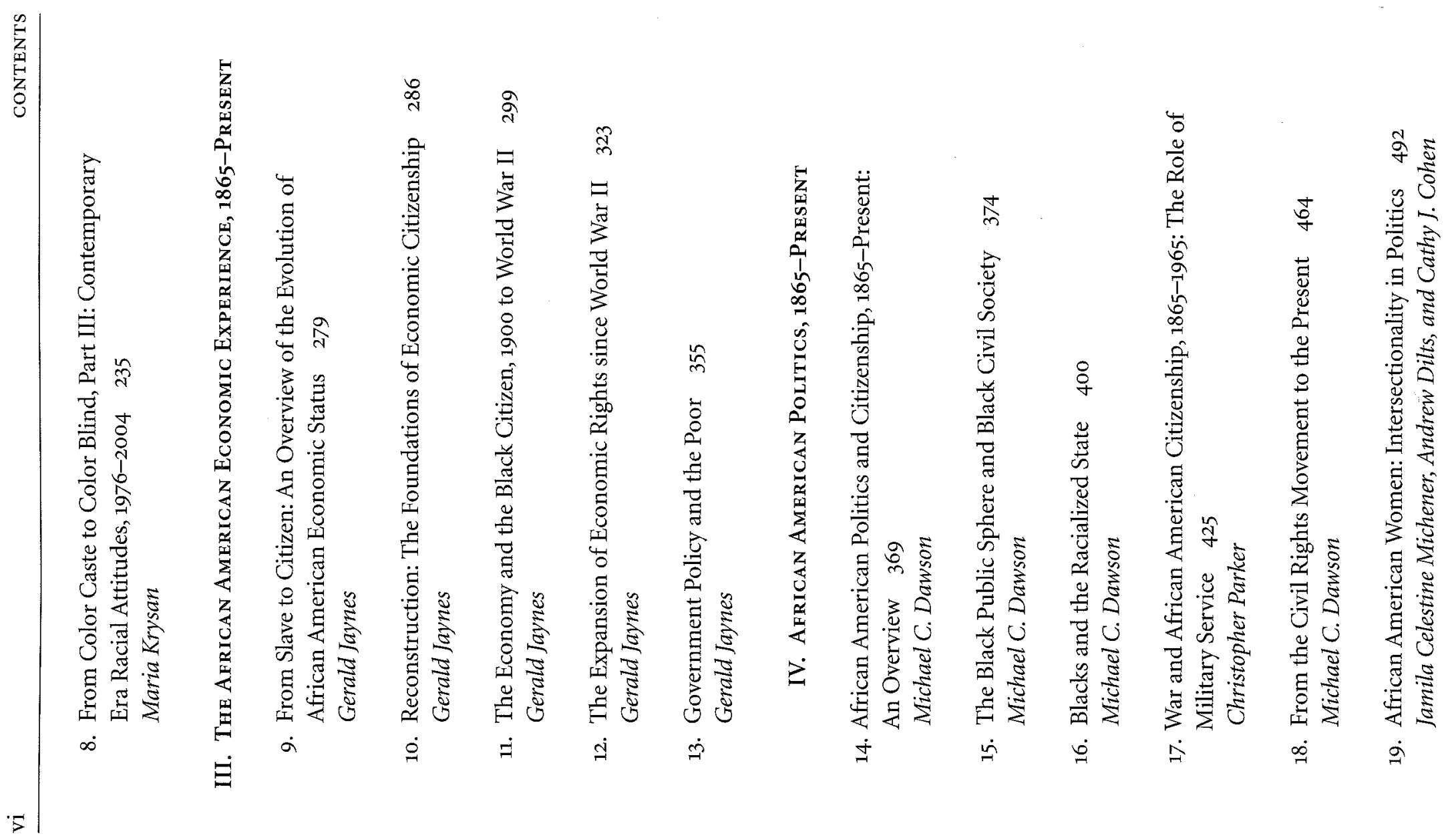




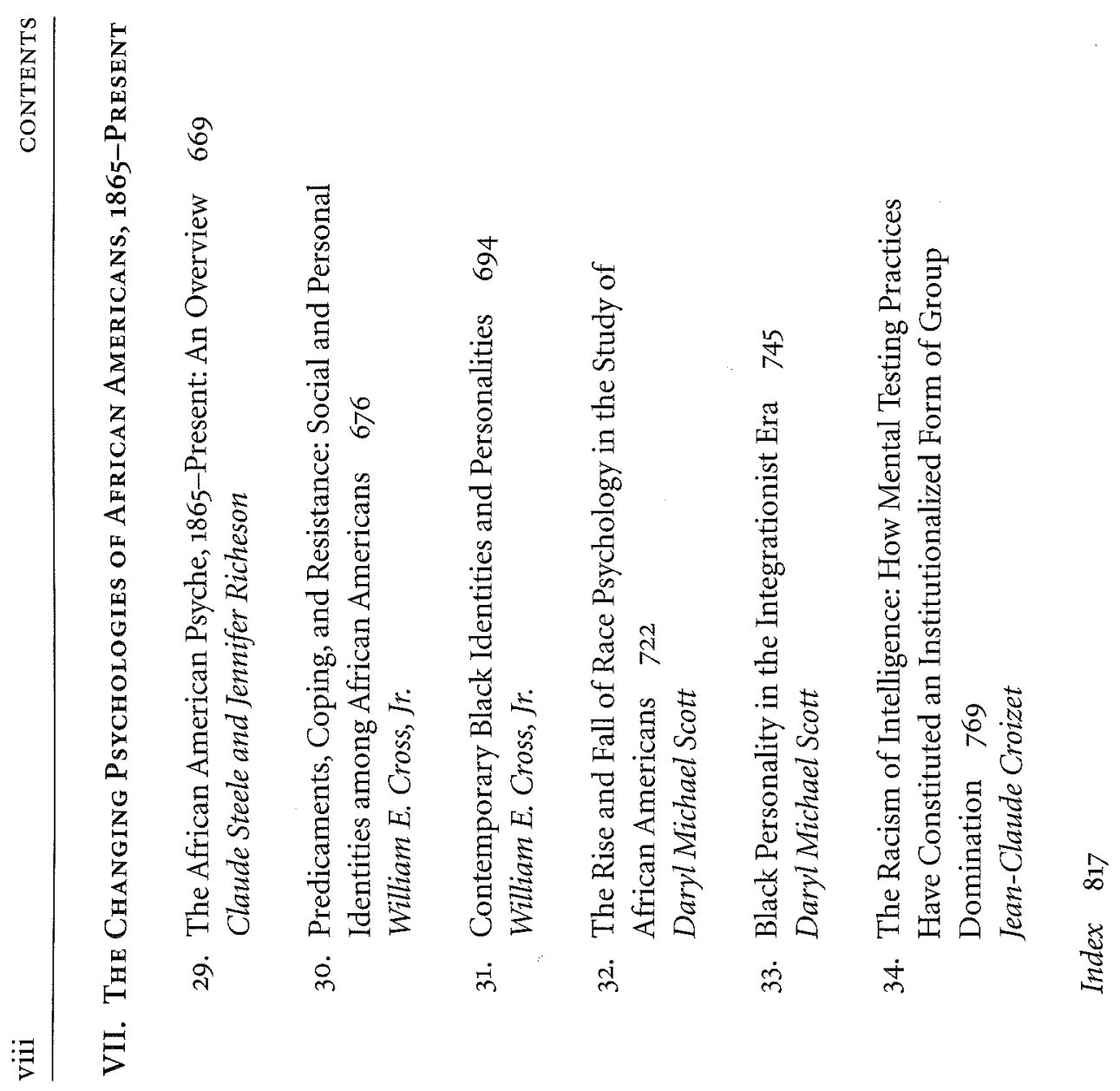




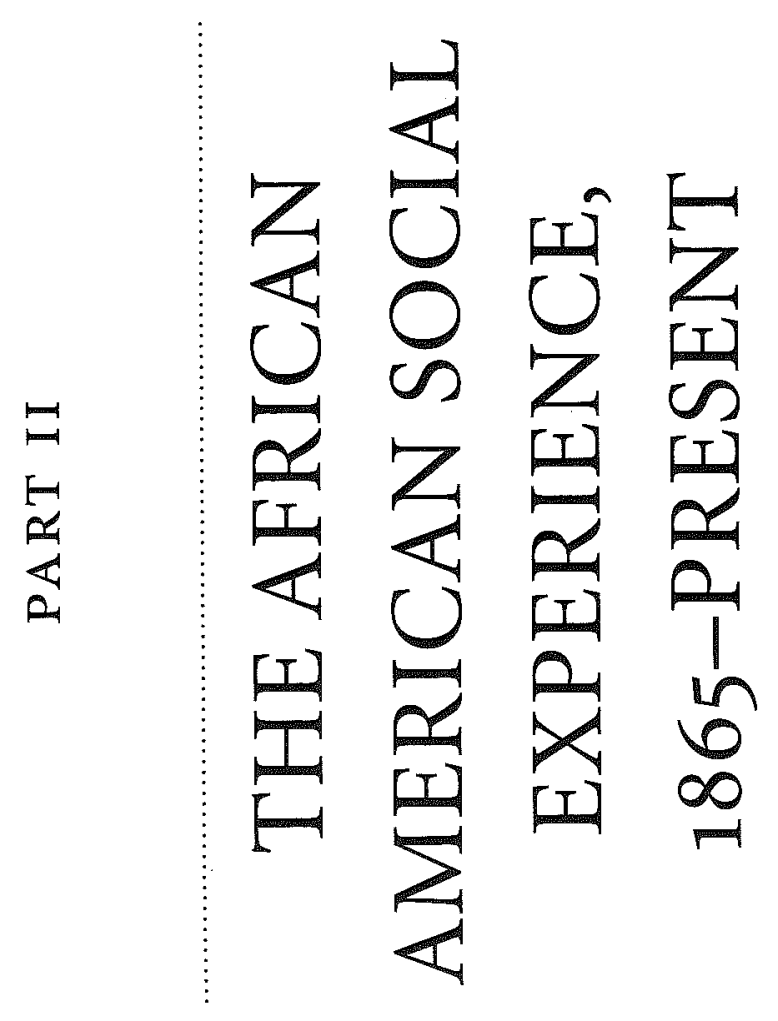




\section{AN AMERICAN CONUNDRUM: RACE, SOCIOLOGY, AND THE AFRICAN AMERICAN ROAD TO CITIZENSHIP}

\section{LAWRENCE D.BOBO}

"I regret to say that in this bright, beautiful, and bountiful country, the specter of race has been ever present. In a country whose founding was not only predicated in large measure on race but also on a profound commitment to the exploitation of one race by another, it could hardly have been otherwise"

- John Hope Franklin, Mirror to America: The Autobiography of John Hope Franklin (2005: 374) 


\section{INTRODUCTION: SOCIOLOGY'S InTERROGation OF THE BLACK-White DIVIDE}

The scholarship on race in the United States is voluminous. Yet few people have probed the thickly layered complexity of African American citizenship with the nuance, irony, and sense of an inescapably human predicament as conveyed by the great sociologist W. E. B. Du Bois. Early on in the first chapter of his immortal book The Souls of Black Folk, Du Bois writes, "One ever feels his two-ness-an American, a Negro; two souls, two thoughts, two unreconciled strivings; two warring ideals in one dark body, whose dogged strength alone keeps it from being torn asunder" (Du Bois [1903] 1999: 11). And therein Du Bois deftly sketched the terms of what remains an ongoing conundrum: Will African Americans achieve full, true, "unmarked" citizenship in the United States or will blacks forever be somehow marginal, lesser, not quite wholly and unequivocally embraced?

The question lies at the heart of one of the great debates of American ideas and scholarly discourse. At one end of this debate we can find those who argue for the American Liberal Tradition. At its core this position maintains that American institutions, values, and culture are deeply liberal. As such, the nation is destined to adopt a broadly expansive and inclusive sense of who belongs and is worthy of respect. Under this perspective, the United States will eventually and inevitably transcend the divisions of race and black-white inequality that marred the nation's founding, arriving ultimately at a place of full comity between blacks and whites.

Several variants and exemplars of the argument exist. Sociologist Nathan Glazer made the case for one prominent version of this argument that he termed "the American ethnic pattern." This view has three core claims. First, that people from the world over would be allowed to enter the United States. And, furthermore, that "all citizens would have equal rights. No group would be considered subordinate to another" (Glazer 1987: 12). Second, that the government would not extend formal and distinctive political recognition and rights to separate ethnic groups. Third, however, that no ethnic group would be compelled to give up its distinctive cultural traditions and practices.

For Glazer, this ethnic pattern reflects a deep-seated inclination and trajectory of American institutions and culture. He argues that:

The American polity has instead been defined by a steady expansion of the definition of those who may be included in it to the point where it now includes all humanity; that the United States has become the first great nation that defines itself not in terms of ethnic origin but in terms of adherence to common rules of citizenship; that no one is now excluded from the broadest access to what the society makes possible, and that this access is combined with a considerable concern for whatever is necessary to maintain group identity and loyalty. (Glazer 1987: 12)

The kernel and potential for the realization of this ethnic pattern, from Glazer's point of view, was established at the very founding of the nation. ${ }^{1}$
An opposite point of view regards race, particularly the black-white divide, as America's tragic flaw. Accordingly, full membership in the polity for African Americans was not only never intended it is perhaps unattainable. For example, philosopher Charles W. Mills questions whether the European Enlightenment era notion of the "social contract" - the normative foundation of the ideal of democratic governance-was ever intended to embrace any nonwhite, non-European peoples. He suggests that the real idea and agreement was to observe equality of rights among those on the privileged side of what is more aptly termed the "racial contract." Thus, Mills declares, "We live in a world which has been foundationally shaped for the past five hundred years by the realities of European domination and the gradual consolidation of global white supremacy" (Mills 1997: 20, emphasis in original). United States democracy and institutions were in no measure an exception to this racial contract. Thomas Jefferson's musings in his Notes on the State of Virginia ([1787] 1972) on the irreconcilable prospect of coequal freedom of black and white in the light of the latter's treatment of black slaves and blacks' profound resentments thereof, as well as Alexis de Tocqueville's claim in Democracy in America ([1848] 1966) that black and white could never exist as equals on American soil, of course, do nothing to contradict Mills argument.

Similarly, civil rights activist and legal scholar Derrick Bell asserted that "racism is an integral, permanent, and indestructible component of this society" (1992: ix). For Bell, each wave of ostensible racial reform and change leaves a fundamental white over black hierarchy in place and attendant patterns of racial categorization as well as a culture of disdain in place. Political scientist Andrew Hacker struck a similar chord arguing that "a huge racial chasm remains, and there are few signs the coming century will see it closed" (Hacker 1992: 219). Even more empirically grounded figures, such as sociologist Joe R. Feagin, adopt a similar position, arguing that "one can accurately describe the United States as a 'total racial society' in which every major aspect of life is shaped to some degree by the core racist realities" (2000: 16). Indeed, Feagin goes so far as to declare:

The United States was originally built as a white-racist republic. It was a principal part of the world racist order created by European colonialism and imperialism to enrich Europeans and impoverish indigenous peoples. The racist institutions established during the slavery period and undergirded by the U.S. Constitution have generated, enhanced, and reproduced the mobility or prosperity of white

Americans for many generations. (Feagin 2000: 66)

Such an assessment of the basic tenor and inclinations of American society and institutions would, of course, sound familiar to many staunch black nationalist thinkers as well. ${ }^{2}$

In between the polar extremes of the American Liberal Tradition thesis and the American Tragic Flaw thesis can be found what political scientist Rogers Smith refers to as America's "multiple traditions." Accordingly, "American politics is best seen as expressing the interaction of multiple political traditions, including liberalism, republicanism, and ascriptive forms of Americanism, which have collectively 
comprised American political culture, without constituting it as a whole" (Smith 1993: 550). Respects for the rights of the individual and a commitment to democratically elected government that is close to the people have existed, therefore, along with strong patterns of inequality attaching to class, race, gender, and sometimes ethnicity (forms of ascriptive Americanism) in Smith's analysis. The exact dominant configuration of these traditions is neither fixed nor inevitably tilted toward more expansive views of who is entitled to full membership in the polity.

Specifically with regard to race and ethnicity, Smith would share the perspective advanced by historian George Fredrickson (1999) and others (Takaki 1987; Glenn 2002; Collins 2005) that the bulk of the American experience has, in fact, involved overt racial and ethnic hierarchy. To wit:

For over $80 \%$ of U.S. history, its laws declared most of the world's population to be ineligible for full American citizenship solely because of their race, original nationality, or gender. For at least two thirds of American history, the majority of the domestic adult population was also ineligible for full citizenship for the same reasons. (Smith 1993: 549)

Yet, from Smith's vantage point, in different eras more progressive configurations of the elements of the American political tradition may rise to dominance. But that is a function of mobilizing efforts as well as underlying political resource and opportunity structures, not some inevitable cultural or institutional destiny.

In the main, I argue that the African American road to full citizenship has involved a distinctive configuration of blockages and detours that have stood in the way of fulfilling this goal. In this respect the argument is a clear rejection of strong versions of the American Liberal Tradition thesis. But, as we will see, I stop well short of embracing the Tragic Flaw thesis, preferring instead the multiple or contending racial orders position. Much real and positive change has occurred. But this change has typically faced resistance and contestation, been achieved only to the extent African Americans and their allies have been able to successfully apply leverage and power resources, and leave the nation still woefully short of extending full, unmarked membership to its sons and daughters of a darker hue.

It will help to clarify what I intend by the notion of full citizenship. In the most elemental sense, borrowing from Evelyn Nakano Glenn, "Citizenship has been used to draw boundaries between those who are included as members of the community and entitled to respect, protection, and rights and those who are excluded and thus not entitled to recognition and rights" (2002: 1, emphasis in original). I intend the term to mean the complete and unmarked enjoyment of the full range of economic and material opportunities and resources, political and legal rights, and broader civil and social recognition and moral esteem that individuals in a society have available to them. In the main, I will refer to these as economic, political, and civil status. Full and unmarked realization of these domains of citizenship would involve little or no connection between an ascribed social characteristic such as race and standing on indicators such as employment status, types of work, and earnings; in terms of unfettered and enforceable access to the vote, political voice, power, contractual rights as well as in one's standing before the law; and in terms of shared or common assessments of human worth, dignity, and claim on membership in the polity.

The larger argument and essay proceeds at two levels. At one level, I review and assess the evolution of theoretical frameworks in sociological research on the changing status of African Americans. At another level, I am concerned with the empirical detail and actual configurations of black status at different points in time. Speaking at the level of theory development, a careful and thorough assessment of the sociological literature on the subject strongly favors accounts that systematically engage the economic, political, as well as the full array of cultural and individual underpinnings of African American disadvantage and constrained citizenship. To emphasize only matters of the economy and polity, as many sociologists are wont to do, is to miss how the sociocultural orientations of black and white Americans may at times work to reinscribe the racial divide even as laws and other formal institutional arrangements change. To emphasize cultural factors above all else, as some sociologists and many popular commentators do, runs the risk of either committing the classic blaming the victim fallacy where black outlooks and orientations become the centerpiece of a fault-finding analysis, or result in exaggerated claims for the stability and analytical centrality of whites' antiblack racial prejudice as the centerpiece of a fault-finding cultural analysis. Instead, I suggest, the most convincing and durable accounts of the changing status of African Americans have been those that wrestle most seriously with integrating economic, political, and cultural dynamics.

Sociologists (Turner and Singleton 1978) and political scientists (Lieberman 2002; Soss, Fording, and Schram 2008) have argued for the explicit integration of structural/institutional arguments about race with the cultural and individual arguments about racial inequality. Some widely accepted conceptual frameworks, like Omi and Winant's (1986) discussion of "racial projects" and King and Smith's (2005) discussion of competing "racial orders," are very congenial to the approach I argue for here. Yet, remarkably few analysts have seriously attempted such integrated approaches (see Brown and Wellman 2005 for one important exception).

In the absence of such an integrated analysis, theorizing reduces to an untenable macro-deterministic logic. In particular, sociological analysis exhibits critical weaknesses as a result of the discipline's strong predilection for structural determinism in the domain of race. Doing so tends to reduce theory to mere typologizing, as mechanisms of change rest at best upon poorly specified, agentless forces and "interests." Close examination of American history on race, especially at key moments of major institutional change, can be revealing in this regard. The decade long period of Reconstruction, despite adoption of a number of formal, institutional efforts and mechanisms for black inclusion and empowerment (which enjoyed a short-lived period of relative success), was eventually brought down through deliberate and conscious social action against that agenda (Steedman 2008). Likewise, in the wake of school desegregation orders and major change in the formal legal structure surrounding the public provision of education, innumerable acts were 
undertaken to undercut, compromise, challenge, and eventually greatly reconfigure such formal institutional declarations (Goldstone 2005; Walker 2009).

The general conceptual point here is that:

History aside, there are also good social scientific reasons to expect that categorical mechanisms of racial stratification will prove resistant to change. We know, for example, that once learned, cognitive structures do not simply disappear. Racial schemas honed over generations tend to persist in the minds of adults and get passed on to children in conscious and unconscious ways. Likewise, institutions and practices that have evolved over centuries do not just cease to exist when laws change. (Massey 2007: 52)

Thus, sociological analyses of race and the status of blacks that insist on institutional or structural level primacy and fail to include cultural and individual attitudes and outlooks are inevitably partial and incomplete.

Racial bias and inequality never rest solely upon institutional design and passive conformity. For me, to state it simply, persistent racial bias and inequality involves racial projects that require action by conscious, meaning-making human actors. Actors whose cultural understandings, expectations, attitudes, and beliefs have been shaped under one institutional regime or order do not quickly or automatically comply with the dictates and demands of a profoundly different institutional regime or order. Indeed, they may well act to scale-back, stymie, subvert, and in some cases largely undo the dictates of a new institutional regime.

More than this, however, I stress the as yet incomplete journey to full citizenship for African Americans. I do not do so out of a commitment to the Tragic Flaw perspective since, in fact, I reject that line of argument. Nor do I so out of a sort of faux radical or "critical" pose that seemingly counts for so much in the academy. No, as the evidence I review suggests, basic racialized categories and identities remain alive and well in the United States; blacks remain disadvantaged across most of the major domains of social life in the United States; even blacks otherwise thought of as middle class face racial constraints, hurdles, and discrimination; and the institutional (economic and political) manifestations of these inequalities are in part sustained and reproduced via the dynamic operation of an antiblack form of cultural racism still active in the American social fabric.

To label the African American journey to citizenship as incomplete is not to embrace an analysis of static and unyielding racial oppression. The black middle class is larger, more influential, and more secure than ever before. Black political incorporation is at a historic high. The segregationist and biological racism of the Jim Crow era is largely defeated. The full reach of all of these changes, however, has not eliminated the social salience of racial categories and identities, enormous race-linked economic inequalities, bitter racial polarization of local and national politics, and disfiguring cultural racism. To suggest that the problem of race endures, however, is not to say that it remains fundamentally constant. I share the view articulated by historians such as Barbara Fields (1982 and 1990) and Thomas Holt (2000) that race is both socially constructed and

historically contingent. As such, it is not enough to declare that race matters or that racism endures. The much more demanding challenge is to account for how and why such a social construction comes to be reconstituted, refreshed, and enacted anew in very different times and circumstances. Making sense of this contradictory circumstance is, indeed, the great challenge of the modern sociology of the racial divide.

\section{LESSONS FROM THE FOUNDATIONS of Sociological Research on The Status of Blacks}

Sociology as a discipline has long engaged in examinations of the working out of this tension between views of race as America's tragic flaw versus views of racial transcendence and comity as the nation's destiny. Indeed, the first major work of American sociology was, in fact, about African Americans and was written by the eminent black scholar W. E. B. Du Bois. In 1899 Du Bois published his landmark work, The Philadelphia Negro: A Social Study ([1899] 2007). Although not then the recipient of the level of lasting attention that the work deserved, The Philadelphia Negro remains an instructive, indeed I argue field-defining, framework for sociological assessments of the changing status of African Americans. Du Bois sought to provide a comprehensive analysis of Philadelphia's Seventh Ward, then the largest concentration of blacks in the city (at the time Philadelphia had the largest number of blacks living outside the South). He documented in systematic and meticulous detail their living circumstances at the close of the nineteenth century. In the broadest sense Du Bois crafted a powerful sociological lens-a view not rooted in biology or nature, nor in psychology, nor in otherwise victim-blaming accounts-for viewing the factors causing black disadvantage. He stressed the social and historically emergent factors that worked to undermine a claim to full mainstream economic, political, and civil status for African Americans.

In most of its pages, and the numerous charts, graphs, enumerations and tables he compiled, Du Bois's The Philadelphia Negro did much more than merely paint a portrait of African Americans in the late 1890 s. He showed and placed in an interpretative context the clear disadvantage blacks faced in health and well-being, employment and terms of work, housing and places of residence, family formation, skill and education levels, involvement in crime, and relative esteem in the eyes of their fellow white Philadelphians and more. Yet he carefully situated each sign of shortcoming or disadvantage in the context of the opportunities, constraints, challenges, and resources that blacks had available to them. And thus, without ideology or unexamined a priori commitments, he advanced a grounded sociological account of the status of African Americans. 
Indeed, his stress upon the social and environmental causes of the conditions in which blacks lived contradicted the then common wisdom that would have stressed blacks' basic capabilities. For Du Bois, an understanding of the disadvantaged status of blacks in Philadelphia, like the nation as whole, required nuanced and sophisticated attention to a complex of factors. In particular, his analysis points to the interplay of six factors in structuring black life chances: (1) comparatively recent emergence from a status of enslavement and forced servitude; (2) population demographic composition effects (such as the disproportion of women to men in black Philadelphia of the time); (3) the economic positioning and intensifying competition with free whites both native born and newly arriving from Europe; (4) the dynamics of racial prejudice and discrimination; (5) the resources, internal structure, dynamics, and leadership of the black community itself; and (6) the moral agency and capacity for self-determination of blacks themselves. Of these, Du Bois clearly placed the economy, in an analytical move that foretold what would become a long-standing sociological tradition, as the central factor shaping the circumstances and life chances of black Philadelphians (Jones 1998).

But it is not merely his emphasis on the irreducible social origins of the status of blacks that merit attention to The Philadelphia Negro: Du Bois's work brought to the fore three other thematic features that are critical to the position taken in this chapter. First, Du Bois highlighted the internal complexity and heterogeneity of the black population itself. Thus, he rejected "a strong tendency on the part of the community to consider the Negroes as composing one practically homogeneous mass" (Du Bois [1899] 2007: 221). For example, Du Bois proposed at least three typologies of social standing in the black population. One scheme was based on types of work or occupational groups, another on levels of income and earnings, and yet a third on a more holistic set of status groupings. With respect to jobs, he showed that blacks were overwhelmingly concentrated in the fields of domestic and personal service, particularly so for black women (88.5 percent versus 61.5 percent for black men). Blacks were also sorely underrepresented relative to whites in the growing industrial sectors of the economy where, for instance, nearly half of white males worked but fewer than one in ten black males held such jobs. The latter constitutes a deeply portentous circumstance given the great expansion in the industrial sectors that occurred in ensuing years.

More striking is that Du Bois pointed to far greater economic heterogeneity in the black population than would have been conceded by most analysts of the time. He classified nearly one in five blacks as poor or very poor based on income. However, he classified nearly half the black population as earning a "fair" income, with the remainder spread across categories of even higher rank such as "the comfortable" ( 25 percent), those in "good circumstances" (4 percent), and those he termed "the well-to-do" (4 percent). Likewise, his schema of status groups pointed to four major "grades" in the black population: an "aristocracy" of about 10 percent who lived in good homes, had a stay-at-home wife, children in school rather than working; a sort of solid working class constituting 56 percent who typically had regular work and pay, decent homes, and could largely keep their children in school; a group he labeled "the poor," estimated at 30 percent, who had limited earnings and spotty employment but were basically honest and not involved in crime; and finally there was what he termed a "submerged tenth" that he defined as "the lowest class of criminals, prostitutes and loafers."

By virtue of this specification of internal complexity, Du Bois was able to draw attention to several considerations. His analysis suggested that, first of all, there was a nascent elite or leadership segment of the black population; a segment that largely went unheralded and unrecognized as a result of the common assumption that blacks constituted an undifferentiated, disadvantaged, and problem riddled mass. ${ }^{3}$ He was no doubt, furthermore, the first social scientist to provide a serious sociological lens on internal class and status frictions within the black population. And, what is more, he makes clear the potent and poignant racial discrimination and bias felt by even those segments of a black community possessed of relatively high skills, resources, and cultural capital. ${ }^{4}$

A second thematic feature of Du Bois's argument in The Philadelphia Negro is the balance he strikes, in a modern vocabulary, between social structure and culture in assessing the status of African Americans. He clearly privileges structure, giving it higher analytical priority, over culture in accounting for black disadvantage. To be sure, any reader of Du Bois will recognize that he routinely points to behavior patterns, conditions, levels of development, outlooks, education, and skill levels that constrain black life circumstances. However, he equally routinely places such facts and discussions in a context of a slave-based and overtly oppressed past, a still deeply stigmatized status, and the otherwise fundamentally common pattern of human response to circumstances of severe hardship and social degradation. In this regard, Du Bois's discussions of black family life and structure as well as his remarks on black involvement in crime are unabashed in speaking of serious and tangible social problems in the black community, even as far back as the late 1890 . He is quick, however, to contextualize these conditions not as an outgrowth of some obdurate group culture or proclivity, but rather as the product of the interplay of historica circumstance and experience with current opportunities and constraints. For Du Bois then, both culture and structure matter and constitute necessary elements of any full account of the status of blacks. Yet at no point in this early work does culture trump structure, or operate above, beyond, and outside of the social conditions that lend cultural patterns their meaning and, indeed, provide their raison d'être. ${ }^{5}$

A third enduring theme to Du Bois's analysis in The Philadelphia Negro concerns the dynamics of racial prejudice and discrimination. Du Bois clearly regarded racial prejudice-negative attitudes, feelings, beliefs, and expectations about blacks-as a constituent factor in structuring where blacks stood in the economy, polity, and larger civil society. Although he never posited a clear conceptual definition of racial prejudice, Du Bois systematically recounted its dynamics and effects. He identified six specific types of effects of prejudice: (1) restriction of blacks to menial work roles; (2) vulnerability to displacement due to competition from native whites or white immigrants; (3) resentment of black advancement and initiative; 
(4) vulnerability to financial exploitation; (5) inability to secure quality education for children or to shelter them from societal prejudice and discrimination; and (6) a wide array of discourteous and insulting treatment in "social intercourse."

This consideration of where Du Bois and The Philadelphia Negro fit in sociology's interrogation of the changing status of blacks underscores, at one level, that at the dawn of the twentieth century, with slavery an institution in the nation's past, African Americans nonetheless stood a very long distance from full citizenship. Although free and migrating in numbers to northern cities such as Philadelphia, blacks encountered a series of challenges and deep disadvantages. Indeed, the black presence in places like Philadelphia was viewed as presenting such a deep complex of "social problems" that a study like Du Bois's was commissioned by leading liberal thinkers of the time (Katz and Sugrue 1998). Of course, below the Mason-Dixon line the institutions of the Jim Crow era, in the form of grandfather clauses, white primaries, poll taxes, literacy tests, and segregated schools, transportation, and other public facilities, were gradually achieving institutionalization. At another level, this return to The Philadelphia Negro provides a useful delineation of a complex, multifaceted sociological approach to parsing the status of African Americans. This approach exhibits several features that I wish to suggest, in a very powerful fashion, withstand the test of time. These signal features involve the relative analytical primacy given structural factors over cultural factors; the internal complexity and heterogeneity of the black community itself; and the interplay of economic status, legal-political status, and cultural outlooks and practices in shaping the circumstances of black social life.

\section{The Turn to Moral Dilemmas, Prejudice, and Personality}

In the work of a later generation of analysts, Du Bois's careful balancing and integration of structural and cultural factors in addressing the status of black Americans would be replaced by more cultural and individual psychology centered analyses. Three works loom large in defining how America's "race problem" came to be understood: Gunnar Myrdal's An American Dilemma: The Negro Problem and American Democracy (1944); Theodor Adorno and colleagues The Authoritarian Personality (1950); and Gordon Allport's The Nature of Prejudice (1954).

An America Dilemma, Myrdal's impressive two-volume work, provided a detailed account of discrimination against blacks across most domains of American social life, debunked claims of innate black inferiority, and examined in detail black institutions (e.g., the black church and political organizations). It was a comprehensive and eye-opening depiction of the status of blacks. Yet, the core legacy of Myrdal was not in the conditions he documented. Myrdal's legacy came in the interpretive context in which he set "the Negro problem in American democracy."
Above all else, Myrdal declared that the race problem was a moral dilemma. He suggested that the United States, more than any other industrial society, possessed an explicit and popularly understood political culture that extolled the values of freedom, individual rights, democracy, equality, and justice. The status and treatment accorded African Americans by their fellow white citizens, plainly enough, sharply contradicted this "American Creed." As a result, most white Americans, in Myrdal's judgment, faced an "ever-raging conflict" between their general values, as embodied in the American Creed, and their specific attitudes and behaviors toward blacks. The "American dilemma" then, was the inherent moral discomfort white Americans experienced in their relation to blacks.

Myrdal also struck an optimistic note about the trajectory of future developments with regard to race in the United States. He saw much to be gained, particularly in the South, from incorporating blacks more fully and equally into mainstream society. In addition, he wrote during a context when wartime mobilization, including bringing blacks into more industrial sectors as well as into the war effort itself, economic development and modernization in the South, and expanding levels of education generally, particularly for younger generations, all pointed in the direction of growing racial liberalization.

Despite the authority and broad influence of Myrdal's work (see Jackson 1990; Southern 1987), empirical evidence supporting the "moral dilemma" hypothesis proved difficult to find. ${ }^{6}$ Instead, theorizing and research took a turn toward an even more micro-analytic posture, adopting a focus on racial prejudice as a key bulwark of racial inequality. In perhaps the most influential statement on the subject, social psychologist Gordon Allport developed a sociocultural model of racial prejudice. ${ }^{7}$ Accordingly, individuals learn and acquire the attitudes, beliefs, and behavioral orientations customary in their social environments. If the culture in which one is raised is infused with negative images, expectations, and beliefs about members of a particular ethnic or racial category, then those are the orientations one learns as a member of that culture. Racial prejudice in specific, then, involved negative feelings and beliefs about minority groups and their members based, as Allport put it, in "faulty and inflexible generalizations." Importantly, the process of acquiring prejudice involved perfectly normal socializing processes and conditions, as well as the ordinary functioning of natural affective and cognitive processes.

A centerpiece of the Allport conception of prejudice was inaccurate stereotypes. Such stereotypes, or beliefs and expectations about the attributes, qualities, and behavioral tendencies of members of a group, were rooted in ignorance rather than direct, varied, and fulsome social experience with members of an out-group. Hence, it was Allport's expectation that contact with members of a disliked out-group should work to reduce racial prejudice. Intergroup contact, particularly under conditions of equal status and in a context of strong incentives to cooperate, would eventually break down racial prejudice. As negative stereotypes and prejudice erode, the discriminatory behaviors and unequal social conditions they help sustain should also be amenable to change. ${ }^{8}$ 
Some theories of prejudice pointed to deeper and more dysfunctional sources of antiblack outlooks and behavior. One such approach came in the theory of authoritarianism. According to Adorno et al. (1950), authoritarianism involved a deepseated personality syndrome producing hostility and aggression toward a wide range of ethnic minority and other groups outside the accepted mainstream (e.g. homosexuals). This hostility was based in a general pattern of rigid, unreflective, hyper-conforming, and highly suggestible ways of thinking. Rooted in a Freudian psychoanalytic tradition, the theory held that the hostility to minority groups and the basic style of thinking were rooted in repressed impulses. These repressed impulses were the outgrowth of a childhood upbringing involving harsh parental socialization demands for conformity and stiff punishment for nonconformity. Individuals (or broader social groupings) high in authoritarianism were held to be likely to engage in individual acts of discrimination and were likely to support repressive, antidemocratic regimes. To wit, if America had a race problem, and if some segments of society, such as the American South or the white working class more broadly (Lipset 1960), had particularly acute problems, one critical source of this problem was likely to be found in higher levels of authoritarianism.

Each of these frameworks for understanding America's race problem focused attention on white America. More than this, each also directed scholars to a concern with subjective states of mind, whether framed as a moral dilemma, as culturally learned negative beliefs and feelings, or as a deep-seated personality syndrome. A substantial shift in focus for sociological thinking and research about race emerged, however, as events of the post-WWII era reshaped the social and political landscape.

\section{Modern Sociology and the Declining Significance of Race Thesis}

In the wake of Myrdal's analysis of the "American Dilemma," Allport's stress on a sociocultural view of prejudice and the benefits of intergroup contact, and Adorno et al's emphasis on the authoritarian personality structure as root sources of intergroup hostility and discrimination, sociology eventually took a decidedly different, more institutional turn. This turn was in part fueled by real world events. The collapse of the major colonial empires in the wake of WWII was one such impetus. In addition, the development of a potent civil rights movement and later the Black Power movement, compelled greater attention to issues of structural and institutional power (see Stone 1985). Hence, over the course of the 1970s, sociology students of racial inequality moved away from a focus on prejudice and discrimination. Instead, perspectives on the black experience that emphasized notions of group conflict, internal colonialism, racial oppression, labor market dynamics, and group power and ideology rose to prominence. Such sociological research took on a much more structuralist, economy-centered, historical, and often comparative scope. For example, Pierre van den Berghe (1967) and Hubert Blalock (1967) developed broad theoretical monographs on the dynamics of race and ethnicity. Works such as these were extended and amplified in the 1970 s by scholars such as Robert Blauner (1972), William Julius Wilson (1973), and Edna Bonacich (1972). Each of whom insisted on a more institutional, political economy approach to understanding the dynamics of race. As Blauner put it in his influential book:

The processes that maintain domination-control of whites over nonwhites-are built into major social institutions. These institutions either exclude or restrict the participation of racial groups by procedures that have become conventional, part of the bureaucratic system of rules and regulations. Thus there is little need for prejudice as a motivating force. Because this is true, the distinction between racism as an objective phenomenon, located in actual existence of domination and hierarchy, and racism's subjective concomitants of prejudice and other motivations and feelings is a basic one. (Blauner 1972: 9-10)

To wit, issues of privilege, group interests, exploitation, and the routine mobilization of biased institutional arrangement and practices - rather than prejudiceshould be at the center of analyses of race.

The intellectual emphasis on the economy, racism, and structures of racial oppression was decisively reshaped by the publication in 1978 of William Julius Wilson's The Declining Significance of Race: Blacks and Changing American Institutions. On the very first page, Wilson boldly declared, "Race relations in America have undergone fundamental changes in recent years, so much so that now the life chances of individual blacks have more to do with their economic class position than with their day-to-day encounters with whites" (Wilson 1978: 1). Furthermore, Wilson suggested, "racial exploitation, discrimination and segregation, schemes that were reinforced by ideologies of racism do not provide a meaningful explanation of the life chances of black Americans today" (ibid.).

His analysis adopted an explicit political economy framework. Although mindful of the role of ideology, norms, and culture surrounding race, Wilson premised his argument on what he called distinctive historical configurations of the economy and the polity. He suggested that we can identify three major stages of race relations that involved a conjunction or intersection of different systems of economic production, on the one hand, and regimes of governance and the political system, on the other hand. These configurations of economy and polity then jointly, according to Wilson, yield characteristic patterns of black-white interaction.

The first two stages, Wilson argued, involved clear circumstances in which race did determine the life chances of blacks. The first, or preindustrial phase, spanned the years from 1640 through the early nineteenth century. This was the era of slavery, the plantation economy, and direct racial caste oppression. The political system, according to Wilson, is decisively influenced by the needs and interests of the white slave-owning class. As challenges to slavery begin to mount and processes of 
industrialization accelerate, particularly outside the South, Wilson suggests that from roughly the 183 os until WWII, we enter the stage of industrial expansion and class conflict. But, this new stage brings with it a reformulation of the core mechanisms and agents of racial oppression. The growing power and influence of the white working class increasingly affects the status of blacks, especially in the years after the Civil War, as blacks are now also free wage laborers rather than enslaved chattel. As white workers are for a time able to successfully constrain black entrance into labor organizing and unions and to exclude them altogether or greatly restrict the black presence in the industrializing sectors of the economy to the least wellpaying, most dangerous and backbreaking jobs, a new regime or epoch of racial oppression emerged.

It is Wilson's treatment of the modern industrial, post-WWII era that aroused controversy. He maintained that this modern era involved a progressive transition from racial inequalities to class inequalities defining the key contours of black life and the character of black-white interaction. A complex series of changes characterize this era. In brief, the emergence of secure collective bargaining rights for workers, biracial unionism efforts, black migration to urban and northern centers, growing black political clout outside the South, potent legal reform strategies (i.e., the Brown v. Board of Education U.S. Supreme Court decision in 1954), and grassroots civil rights movement organizing and protest, as well as the eventual enactment of antidiscrimination and affirmative action policies, decisively reconfigured where blacks stood in the economy and the polity. So much so, Wilson contended, that where blacks stood in the economy and the human capital attributes they brought to the market as individuals mattered much more than race or racial discrimination per se in defining the likely quality of life experience a black person would enjoy. He did not argue, as some critics implied, that race had no consequence. In particular, he forecast increasing race-inflected political struggles over control of municipal and city governments and resources as blacks strove to increase their influence as recent arrivals to major urban centers around the country. But, he insisted, one could no longer credibly argue that the overarching fact of a distinct racialized status - as slaves or as categorically excluded and marginalized laborers-defined the larger life prospects of blacks.

\section{The Immigrant Analogy Hypothesis}

In the wake of the gains of the civil rights movement era, some scholars began to suggest that blacks would eventually enjoy the same sort of social mobility and process of incorporation in the American mainstream as experienced by earlier waves of immigrants from Europe. Irving Kristol advanced this idea in a major essay in 1966 in The New York Times Magazine (Kristol 1966). He suggested that although there were some reason to regard antiblack prejudice as more potent than, say, anti-Irish prejudice had been, the legal and political supports for antidiscrimination were by then far more potent and institutionalized than had been the case in earlier eras. Furthermore, he argued, what handicaps blacks faced had more to do with the structural opportunities they encountered and the degree of positive reception they received from the dominant white society than from any durable deficiencies of black culture. As he concluded, blacks "in comparison with previous waves of immigration to the great cities, they are 'making out' not badly at all” (Kristol, 1966: 142).

This argument would be elaborated and extended by Nathan Glazer. In a 1971 essay, Glazer pointedly questioned the growing assumption that blacks encountered a uniquely potent form of bias and prejudice better understood as a sort of distinctive "racism." He suggested, on the contrary, that "neither in America, nor elsewhere, are race and ethnicity categories so different that the processes that affect the assimilation and integration of ethnic groups change completely when groups of different race are involved" (Glazer 1971: 447). European immigrant groups had encountered bias and prejudice. Blacks, he maintained, were wrestling with essentially the same problem.

Glazer pressed on, however, to draw a substantive and, he argued, positive political implication from such an analysis. To wit, "If one sees continuity then one may take an optimistic view of the American black position. Not only 'if we made it, why don't they', but 'if we made it, so will they'" (Glazer 1971: 449). He concluded, "I believe it is possible to see the position of blacks in Northern cities in ethnic terms, that is, to see them as the last of the major groups, the worst off, but due to rise over time to larger shares of wealth and power and influence. This is a possibility - in harmony with as many facts as any other" (Glazer 1971: 460). Such an assessment of the mechanisms undergirding black disadvantage and the trajectory of future development of the racial divide would subsequently fuel Glazer's critical challenge to affirmative action policies (Glazer 1975).

A meticulous and far-reaching empirical assessment of the immigrant analogy hypothesis was undertaken by sociologist Stanley Lieberson (1980). Lieberson's detailed analysis documented the many ways that blacks in the mid-nineteenth century through the early decades of the twentieth century were more severely disadvantaged and faced more durable barriers to mobility than various southern, central, and eastern European immigrant populations. His work ruled out differences in simply the experience of slavery (e.g., there were eras of major setbacks for blacks, especially outside the South, clearly not traceable to a direct legacy of slavery), or in group cultural orientations and values (e.g., he reviews the arduous and steady efforts blacks made to obtain better schooling and education for their children). ${ }^{9}$ One central difference that Lieberson stressed is that blacks had to wage a long, hard-fought effort for even basic respect of their elemental citizenship rights, a circumstance not encountered by European immigrants.

What then makes for the difference in the experience of African Americans? Lieberson directs final analytical and interpretive attention to the dispositional expectations created among whites by the initial terms and conditions of contact of 
the groups and the extent to which blacks were construed as major labor market threats to white workers. Accordingly, he explains:

There are two key features that distinguish blacks from other nonwhite groups in the United States and which help explain their different outcomes. First, an exceptionally unfavorable disposition toward blacks existed on the part of dominant white society due to the slave period and the initial contact with Africans. Blacks enter into competition as free people, but they are unable to shake off easily the derogatory notions about them and the negative dispositions toward blacks which go back to the slavery era. Of course, this was not a problem for other nonwhite groups. Second, the threat of Asian groups was not anywhere as severe because migration was cut off before their numbers were very large... The cessation of sizeable immigration from Asia for a number of decades on the one hand indicates how quickly threatened whites were by Asian groups. On the other hand, this very cessation made it possible for those who were here to avoid eventually some of the disadvantages that would occur if there were as many of their compatriots in the country as there were for blacks. (Lieberson 1980: 368)

His work thus called into question any easy assumption of parallel trajectories of progress.

Part of what Lieberson's work shows, however, is the importance of not leaving culture out of the analysis. His core interpretation stresses that, while placement in the economy and demographic factors such as size of the group mattered critically, these considerations operate in conjunction, fundamentally, with the fact that blacks encountered and continue to encounter a strong latent cultural dispositional that resists allowing them full membership in the polity.

\section{A New Focus on Urban Poverty}

The larger political context changed sharply in the wake of the publication of works like The Declining Significance of Race (Wilson 1978) and A Piece of the Pie (Lieberson 1980). With the 1980 Presidential election, conservative Republican Ronald Reagan rose to the White House and with his electoral success a new wave of conservative analyses of social problems and social policy rose to dominance. Thus, cultural interpretations of social inequality, including black disadvantage, came to occupy an unprecedented popularity and policy-making relevance. ${ }^{10}$

William Julius Wilson led the way in crafting a sociologically grounded response to this conservative, cultural and individual behavior centered analysis. Wilson opened The Truly Disadvantaged (1987) by speaking directly about problems of crime, out-of-wedlock childbirth, and welfare dependency; a complex of problems widely seen as defining urban inner-city life. Candor about the extent of these problems, Wilson argued, was the only way for liberal analysts to regain credibility with the American public and with policy makers. Wilson dismissed as outdated the political left's analysis from the perspective of racism and discrimination. He dismissed as ahistorical, factually incorrect, and victim-blaming the political right's analysis from the perspective of individual values and group culture.

In the place of these two competing paradigms, Wilson put forward a threepart analysis. First, he proposed that America's urban centers had witnessed the emergence of a new urban "underclass," or truly disadvantaged group. These innercity black residents, as a result of historic discrimination, had low skill levels and were not well positioned to respond to major changes in the structure of the economy.

Second, Wilson observed that inner cities were losing the types of relatively low-skill, well-paying, unionized jobs that were once abundantly available in cities. This decline was attributable, in his analysis, to the deconcentration of industry as heavy-goods production and manufacturing moved increasingly from proximity to central city cores to suburban and even ex-urban locations. More importantly, Wilson saw job loss as attributable to the deindustrialization of the American economy, especially in urban centers, as aspects of a huge shift toward service-oriented, information processing, technology-related high skill work. This confluence of circumstances results in a skills/spatial mismatch wherein low-skill, inner-city blacks were less and less competitive for high-skill, high-wage jobs, such as in finance, banking, communications, law, insurance, and the like available in central city areas. A key impact of fundamental restructuring of this kind and scale was a sharp rise in the rate of black male joblessness, with long-term unemployment and marginal employment prospects becoming a commonplace experience. Joblessness not only heightened the experience of poverty, but it reduced the likelihood of marriage for both black men and women. Wilson argued that men are reluctant to marry when they cannot provide economically for a family and women do not find men with limited employment prospects to be promising marriage partners.

Third, these circumstances resulted in the profound social disorganization of communities, according to Wilson, because the "underclass" suffered great isolation from mainstream social values. Underclass communities involved areas of extremely high concentrations of poverty, where 40 percent or more of the residents were below the poverty level. Contributing to this growing isolation for the underclass was a greater mobility for middle-class and skilled working class blacks who were better able to leave inner-city ghetto communities in search of job opportunities opened for them by the civil rights movement and policies such as affirmative action. Those left behind, as a result, were the poorest of the poor. This "underclass" mix is the group who Wilson associated with the problems of welfare dependency, out-of-wedlock childbirths, juvenile delinquency, and crime.

Culture too played a role in Wilson's analysis. He wrote extensively about counter-normative and ghetto-specific behaviors observed among the new urban poor. But Wilson expressly linked these cultural patterns to the degree of concentration of disadvantage and extreme isolation from the rest of society characteristic of underclass neighborhoods.

Wilson's ideas helped to usher in a decade of intensive focus on the circumstances of low-skill, inner-city minority workers. But it did not do so without 
controversy. One of the first lines of sustained critique of Wilson came from Herbert Gans (1995), who took strong objection to the use of the term "underclass." Gans suggested the term merely became another stigmatizing epithet that encouraged focusing on the behavior of individuals rather than on the structural circumstances of groups and communities. And certainly there were many commentators on the right who used Wilson's terminology in this fashion, ignoring much of the rich sociological context and argumentation he advanced. Wilson ultimately moved away from using the "underclass," preferring instead the terms "urban poverty" or "ghetto poverty" in an effort to emphasize the properties of such types of structural placements in the economy (Wilson 1996). Other scholars, even some of those who trained as part of Wilson's study of Chicago urban poverty, developed significant critiques and reformulations of cultural takes on the behavior of low-income innercity blacks (see Duneier 1992; Young 2004; Smith 2007).

\section{A Return to Race-Centered Analyses}

A mixture of real world social and political events as well as intellectual trends and research findings combined to shift sociology more in the direction of a racecentered analysis. Some of these contextual factors involved sociopolitical trends and others involved intensively publicized specific events. The often fractious and bitter politics that emerged when blacks began to contend in a serious fashion for mayoral offices and higher posts in many cities and states (Kaufmann 2004; Thompson 2006) raised concerns about racial tensions. Another of the trends encouraging this change in framework involved the steady waning of pressure for real desegregation of public schools amid evidence of some degree of resegregation taking place (Hammond 2004). Similarly, a steady array of successful legal and political challenges to affirmative action policies and practices in both the arenas of employment and higher education called into question the durability of the policy push for full black incorporation. There were, in addition, highly visible and sharply polarizing events such as the use of the Willie Horton political ads in the 1988 presidential campaign, the 1991 airing of the Rodney King police beating video, the 1992 Los Angeles riots in the wake of the exoneration of the officers involved in the King beating, the highly divisive O. J. Simpson criminal murder trial beginning in 1994, and the 1995 "Million Man March" on Washington, DC.

Despite these many developments, a return to race-centered analysis can be read as deeply ironic. One might have forecast a very different trajectory in the light of the many successes of the civil rights movements. The 1954 Brown v. Board of Education decision, the successful culmination of the Montgomery bus boycott and rise of Dr. Martin Luther King, Jr. to national prominence by 1956, the 1963 march on Washington and King's historic "I Have a Dream" speech, passage of the 1964 Civil Rights Act (CRA), of the 1965 Voting Rights Acts (VRA), and later the 1968 open housing laws could all be read as the deep and sweeping institutionalization of a profound "minority rights revolution" (Skrentny 2002).

At another level, the extent of political mobilization and open conflict and contestation surrounding these gains was substantial. Indeed, the VRA passed only one week before the eruption of the Los Angeles-Watts riot of 1965. The 1968 open housing legislation was enacted within days of the assassination of Martin Luther King, Ir. In between these jarring events, the emergence of the Black Power slogan and movement, innumerable protest marches and demonstrations, and massive urban riots over the "long, hot summers" of 1967 and 1968 would roil the nation. And as school desegregation efforts moved North in the 1970s, a whole new set of clashes and protests as well as legal, administrative, and individual strategies of delay and avoidance began.

Scholars across the social sciences observed these developments and, despite the many gains of the civil rights era, began to identify new forms and expressions of racism. Experimental social psychologists were among the first to do so based on field experiments on actual social behavior. Signs of clear racial bias in helping behavior inspired the formulation of the theory of aversive racism in the $1970 \mathrm{~s}$ (Gaertner and Dovidio 1986). Political psychologists probed both white reactions to the urban riots of the 1960 s and the early efforts of blacks to attain mayoral office in places like Cleveland, Ohio, Gary, Indiana, St. Louis, Missouri, and Los Angeles, California. These reactions and political contests began to point to the emergence of a set of post-Jim Crow, post-biological racisms that expressed deep resentment of the rhetoric, demands, gains, and politics of black Americans. This led, specifically, to the formulation of the theory of symbolic racism in the 1970s (Sears 1988), later reformulated very convincingly as the theory of politicized racial resentments (Kinder and Sanders 1996).

Three interrelated lines of development decisively shifted mainstream sociological attention back to a more central concern with race. First and foremost, Douglas Massey and Nancy Denton published their influential book American Apartheid: Segregation and the Making of the Underclass (1993). In part a response to the economy-centered analysis of urban poverty, Massey and Denton argued that the deliberate racial segregation of communities was the key factor in the rise of concentrated ghetto poverty. On the basis of careful historical, demographic, and econometric simulation analyses, they showed how the emergence and maintenance of racial barriers in the housing market were critical to the development of extremely disadvantaged inner-city communities. As a result, they also pointed out the strong contemporary relevance of racial discrimination in the housing market to larger patterns of modern inequality, thereby helping to resuscitate a focus on processes of racial discrimination.

A second crucial line of development involved renewed attention to the experiences and outlooks of the black middle class. Journalist Ellis Cose (1993), sociologist Joe Feagin (Feagin and Sikes 1994), and political scientist Jennifer Hochschild (1995) all drew attention to a deep wellspring of resentment among comparatively affluent blacks over the level of everyday racial bias, insult, and discrimination they 
encountered. Feagin and colleagues, for example, documented myriad forms of micro-interactions that middle-class blacks had with whites in educational institutions, corporate workplaces, and numerous public spaces such as restaurants, stores, and the like where blacks reported encountering biased, insulting, or openly discriminatory treatment.

A third line of research pointed to the ongoing salience and effects of negative racial attitudes, particularly of antiblack stereotypes. A major study carried out by the General Social Survey of the National Opinion Research Center (NORC) pointed to the persistence of negative images of blacks among whites (Bobo, Kluegel, and Smith 1997), with such negative stereotyping playing an important role in public thinking about how social policy should (or should not) respond to inequality (Bobo and Kluegel 1993; Gilens 1999). Such negative stereotypes would prove to be a critical ingredient in the reproduction of patterns of racial residential segregation as well (Charles 2006). ${ }^{11}$

A variety of related developments also served to advance a more central focus on race. For example, historians and students of American culture also launched an emphasis on "whiteness studies." Such research traced the ways in which establishing a claim to whiteness was essential to the historical processes of economic, political, and cultural assimilation for many European immigrants to the United States. ${ }^{12}$ Likewise, sociologists became far more serious and systematic about explicitly theorizing race (Winant 2000; Zuberi 2001) and argued for a new color-blind racism (Bonilla-Silva 2010)

\section{The Black-White Divide Today}

Many commentators regard the modern era as a time of pronounced heterogeneity, mixing, and increased fluidity of racial backgrounds in the United States (Omi 2001). The 2000 U.S. Census broke new ground by allowing individuals to "mark more than one" box when it came to designating a racial background. Indeed, great political pressure and tumult led to the Census decision to move in a direction that more formally and institutionally acknowledged the presence of increasing mixture and heterogeneity in the American population with regard to racial background. And nearly 7 million people exercised that option in 2000 (Williams 2006). The successful rise of Barack Obama to the office of the presidency of the United States, the first African American to do so, as a child of a white American mother and a black Kenyan father has only accelerated the sense of the new found latitude and recognition granted to those who claim a mixed racial heritage.

Despite Obama's electoral success and press attention to the change in the U.S. Census, it is astonishing the degree to which the great overwhelming majority of Americans identified with one and only one race. As figure 2.1 shows, less than 2

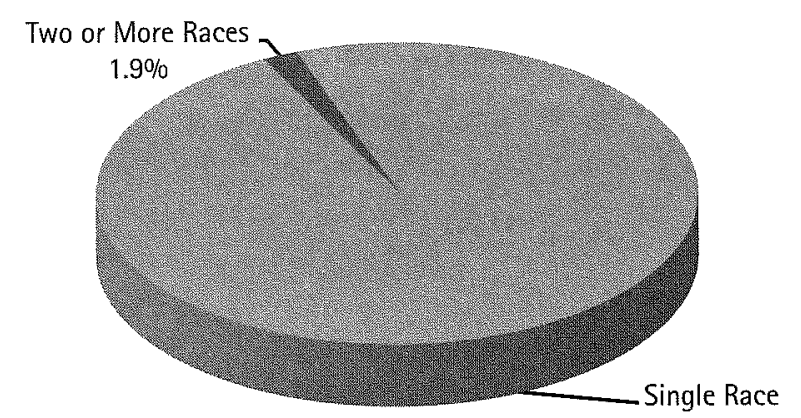

Figure 2.1 Single race and two or more race population, U.S. Census 2000 (non-Hispanic)

Source: U.S. Census Bureau, Census 2000 Redistricting (Public Law 94-171) Summary File, table PLI.

percent of the population "marked more than one" box during the 2000 U.S. Census. Fully 98 percent did exactly that and no more. I claim no deep rootedness or profound personal salience for these Census enumerated identities. Rather, it is important to be mindful that the level of "discussion" and contention around mixture, hybridity, mixed raciality, etc. is somehow, at least judged against this simple yardstick, far out of proportion to the extent to which most Americans actually appear to classify themselves in such terms.

Moreover, even if we restrict attention just to those who did "mark more than one" box, it is somewhat surprising to learn, as figure 2.2 shows, that two-thirds of these mixed race individuals involved two groups other than black (that is, namely Asian-white, American Indian/Alaskan Native-white, Native Hawaiian and other Pacific Islander-white, or Asian in combination with one of these others). Some degree of mixture with blacks constituted just under a third of the total pool of mixed race identifiers. Given the historic size of the black population and, particularly, extended length of contact with white Americans, this is a remarkable result and says something powerful, at the least, about the potency of the black-white divide.

Still, the ethno-racial landscape in the United States is changing. As figure 2.3 shows, as of the 2000 Census whites constituted just 69 percent of the total U.S. population, with Hispanics and blacks both around 12 percent of the total. This distribution represents a substantial decline from the percentages of white twenty or even more so, forty years ago, prompting some to speculate about the coming "end of whiteness" (Hsu 2009).

With continued immigration, with differential group fertility patterns, and with the continued degree of intermarriage and mixing, these patterns are unlikely to remain stable. Figure 2.4 shows the Census racial distribution projections out to the year 2050. First and most obviously, the figure continues to show a steady and rapid decline in the relative size of the white population with 


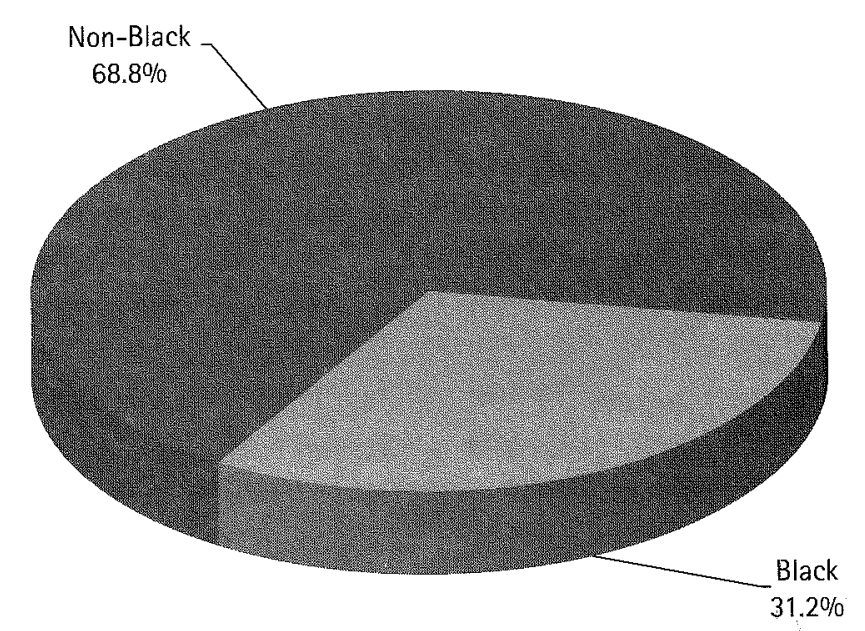

Figure 2.2 Percent of two or more race population choosing black in combination with one or more other races (non-Hispanic)

Source: U.S. Census Bureau, Census 2000 Summary File 1, matrices P8 and P10.

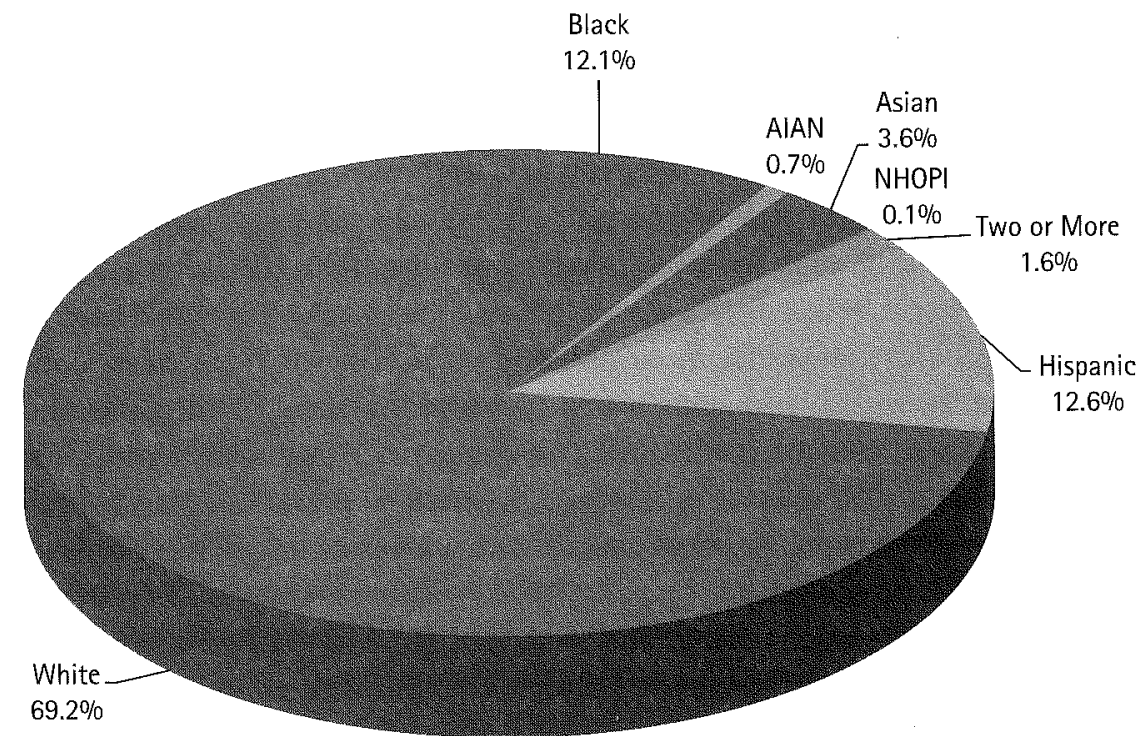

Figure 2.3 Racial and ethnic composition of the United States, 2000 (Note: Figures may not sum to exactly $100 \%$ due to rounding.)

Source: U.S. Census Bureau, Census 2000 Summary File 1, matrices P8 and P10.

the forecast that somewhere between 2040 and 2045 whites will cease to be a numerical majority of the population (and this change will quite possibly happen much sooner than that date). The relative size of the Hispanic population is expected to grow substantially where the black, Asian, Native Hawaiian and other Pacific Islander, as well as American Indian and Alaskan Native groups

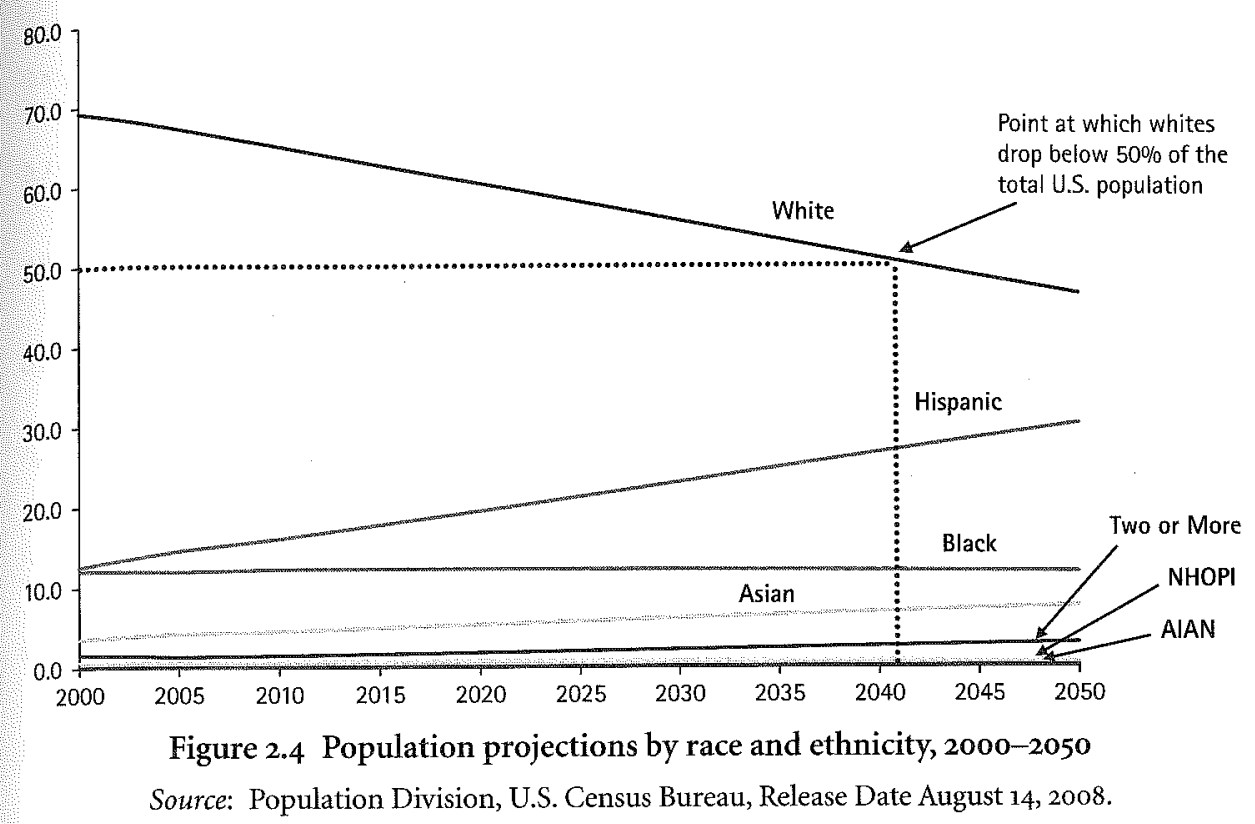

remain relatively constant. This figure makes it clear, at least by strong implication, that pressure to transform our understanding of racial categories will continue.

A decade ago sociologist Herbert Gans (1999) offered the provocative but well-grounded speculation that we would witness a transition in the United States from a society defined by a great white-nonwhite divide, to one increasingly defined by a black-nonblack fissure, with an in-between or residual category for those granted provisional or "Honorary White" status. As Gans explained: "If current trends persist, today's multiracial hierarchy could be replaced by what I think of as a dual or bimodal one consisting of 'nonblack' and 'black' population categories, with a third 'residual' category for the groups that do not, or do not yet, fit into the basic dualism" (Gans 1999: 371). Most troubling, this new dualism would, in Gans's expectations, continue to bring a profound sense of culturally defined moral undeservingness and stigma for those assigned to its bottom rung.

Gans's remarks have recently received substantial support from demographer Frank Bean and his colleagues. Based on their extensive analyses of population trends across a variety of indicators, Bean writes, "A black-nonblack divide appears to be taking shape in the United States, in which Asians and Latinos are closer to whites. Hence, America's color lines are moving toward a new demarcation that places many blacks in a position of disadvantage similar to that resulting from the traditional black-white divide" (Bean et al. 2009: 215). Thus, even as the ethno-racial landscape grows more complex, there remain strong signs that a black identity, associated with disadvantage and stigmatized status, continues to define the American social order 




Figure 2.5a Changes in the occupational distribution for white males, 1960-2007

Source: Miriam King, Steven Ruggles, Trent Alexander, Donna Leicach, and Matthew Sobek. Integrated Public Use Microdata Series, Current Population Survey: Version 2.o. [Machine-readable database]. Minneapolis: Minnesota Population Center.

Note: ${ }^{1}$ The occupational categories are derived from the 1950 Census Bureau occupational classification system for occupational data using the following guideline: Middle-Class = "Clerical and Sales," "Technica and Professional," "Managers, Officials, and Proprieters"; Skilled Working Class = "Craftsmen," "Operatives"; Unskilled Working Class = "Service Workers," "Laborers"; Farm = "Farmers," "Farm Laborers." The Universe includes the following:

1960-1970: Persons age 14+ who had worked within the previous ten years; not new workers. 1968-2000: Persons age 16+ who had worked within the previous five years; not new workers.

If something about basic racial categories seems to stand constant, that does not mean the relative positioning of blacks on a variety of other key social indicators has remained so. Consider first the matter of the degree of racial economic inequality. There has been considerable expansion in the size, security, and arguably salience and influence of the black middle class. Figures $2.5 \mathrm{a}$ and $2.5 \mathrm{~b}$ show trends since 1960 in the percentage of white males and black males, respectively, who have middle-class, skilled working class, unskilled working class, or farm-related occupations. Among whites the percentage middle class rose from about 33 percent in 1960 to approximately 50 percent by 2000 where upon it reaches a plateau. For black males there is a much sharper rise in the percent middle class, going from a low point of less than 10 percent in 1960 to approximately 40 percent in the post-2000 era. As a result of this change, the black-white gap in holding middle-class occupations among men narrowed substantially. Perhaps most striking here is that among

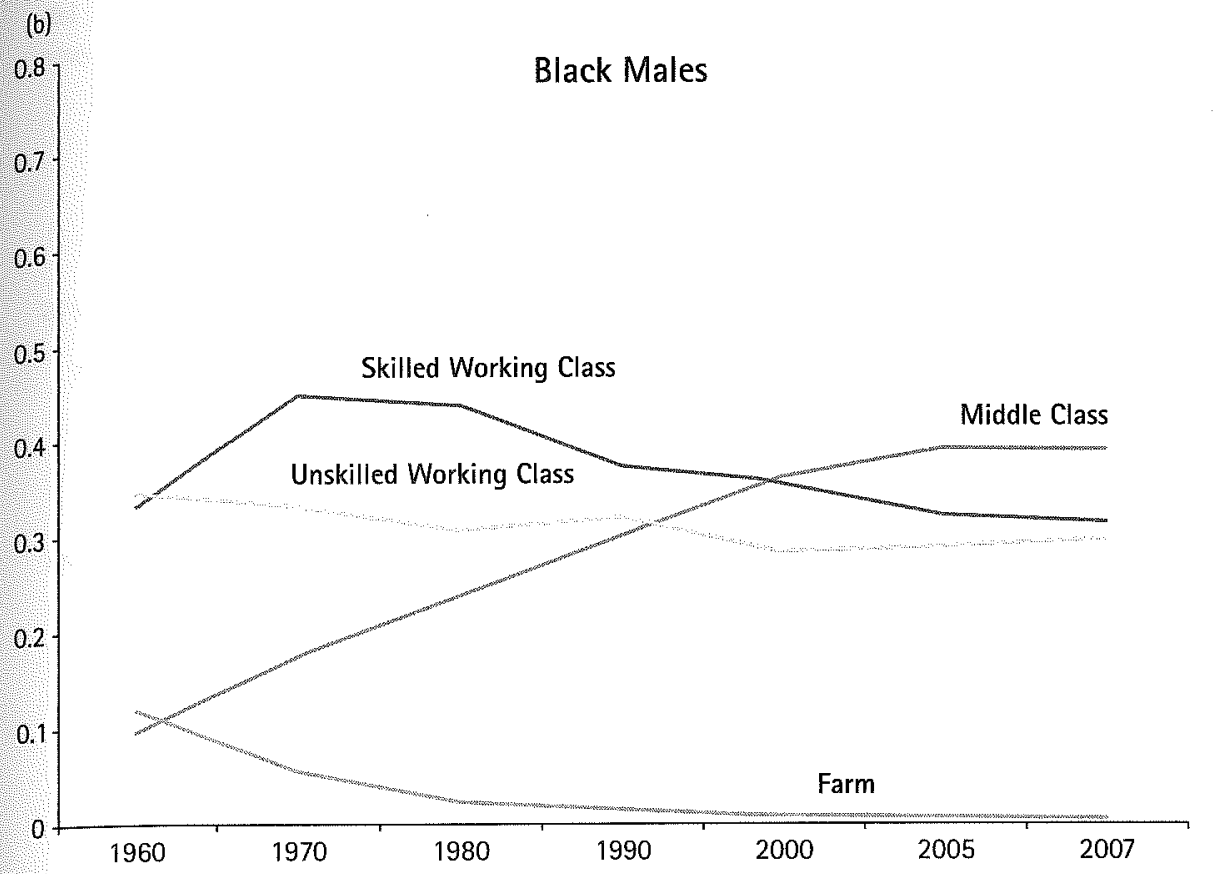

Figure 2.5b Changes in the occupational distribution for black males, 1960-2007

Source: Miriam King, Steven Ruggles, Trent Alexander, Donna Leicach, and Matthew Sobek.

Integrated Public Use Microdata Series, Current Population Survey: Version 2.0 [Machine-readable database]. Minneapolis: Minnesota Population Center.

Note: ${ }^{1}$ The occupational categories are derived from the 1950 Census Bureau occupational classification system for occupational data using the following guideline: Middle-Class = "Clerical and Sales,"

"Technical and Professional," "Managers, Officials, and Proprieters"; Skilled Working

Class = "Craftsmen," "Operatives"; Unskilled Working Class = "Service Workers," "Laborers"; Farm = "Farmers," "Farm Laborers." The Universe includes the following:

1960-1970: Persons age 14+ who had worked within the previous ten years; not new workers. 1968-2000: Persons age 16+ who had worked within the previous five years; not new workers.

blacks in 1960s just one in ten men were in middle-class occupations and the lion's share of blacks were, in fact, in the unskilled working class. By 2007, fully two out of five black men were in such middle-class jobs, exceeding the number in either the skilled or unskilled working class categories.

Even using these broad occupational class groupings a real black-white gap of about to percentage points remains. A more refined analysis, presented in figures 2.6a and 2.6b, separates the middle-class occupational category into "professional and technical occupations," "managers, officials, and proprietors," and "clerical and sales" positions. As figure 2.6a shows, the modal occupational category for white males in recent years, constituting nearly 20 percent, involve the professional and technical category. For black males, however, fewer than 15 percent in recent years are in the professional and technical fields, with clerical and sales positions constituting the largest fraction of the black male middle class. 


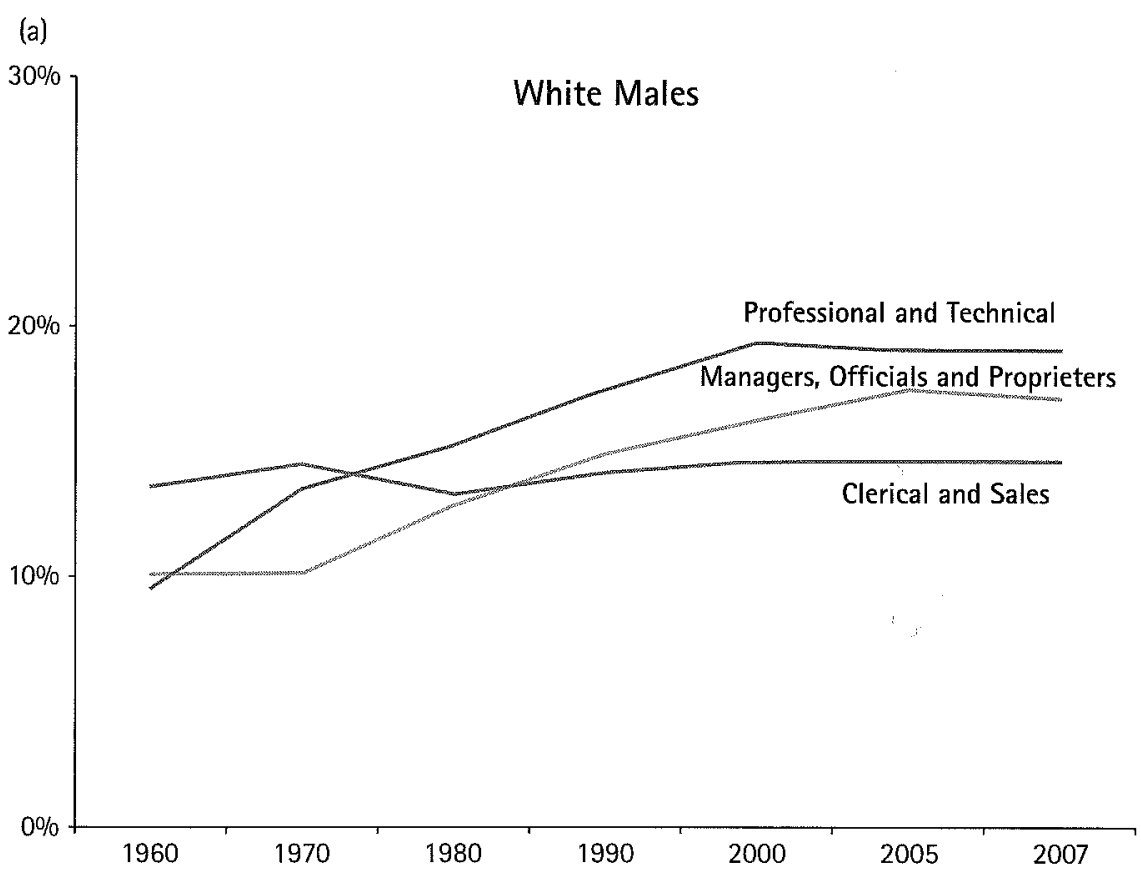

Figure 2.6a Changes in the middle-class distribution of white males, 1960-2007

Source: Miriam King, Steven Ruggles, Trent Alexander, Donna Leicach, and Matthew Sobek. Integrated Public Use Microdata Series, Current Population Survey: Version 2.o [Machine-readable database]. Minneapolis: Minnesota Population Center.

In sum, even within the middle-class occupational category there is considerable heterogeneity and remaining racial inequality. Whites males are far more likely to be in the managerial, technical, professional, and business proprietorship categories than are black males who are more heavily located in clerical and sales positions. Still this is a story of a huge transformation, occupational upgrading, and reduction of inequality in the place of black men in the American occupational structure.

Figures 2.7a and 2.7b repeat the broad occupational class categories for white and black women, respectively. White women in the labor force have long been overwhelmingly concentrated in middle-class jobs, with greater than 50 percent in this category as far back as 1960 and reaching 70 percent in more recent years. Black women undergo an enormous transformation, moving out of unskilled working class jobs (i.e., maids, household servants, and the like) and into middle-class occupations in the post-1960 period. As figures $2.8 \mathrm{a}$ and $2.8 \mathrm{~b}$ show, however, a more fine-grained view of the middle-class occupational category reveals more similar distribution of white and black women than of white and black men. Women in general are more heavily represented in the clerical and sales type jobs, though this represents a declining fraction of white female workers. Both white and black females exhibit a rise in the percentages that hold jobs in the professional and technical

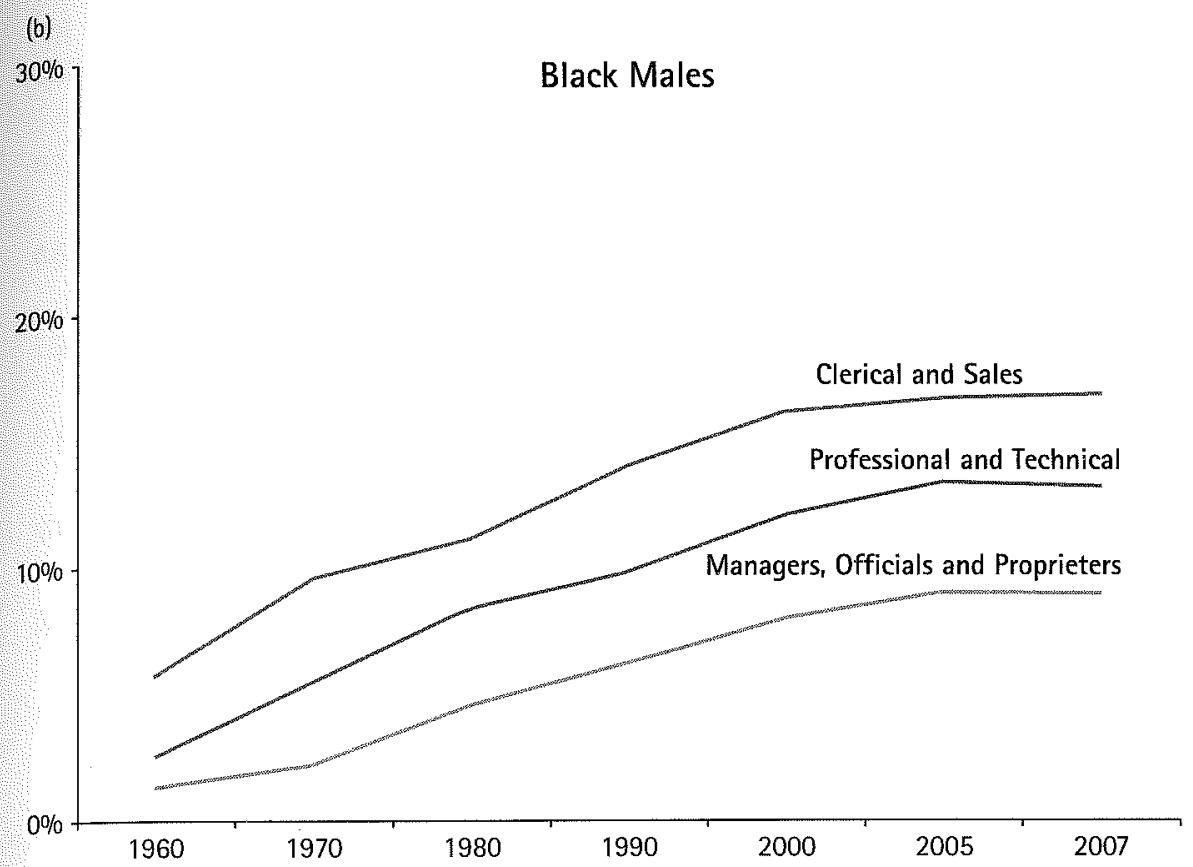

Figure 2.6b Changes in the middle-class distribution of black males, 1960-2007

Source: Miriam King, Steven Ruggles, Trent Alexander, Donna Leicach, and Matthew Sobek. Integrated Public Use Microdata Series, Current Population Survey: Version 2.0 [Machine-readable database]. Minneapolis: Minnesota Population Center.

fields as well as in the managerial category. By 2007 nearly equal percentages of white and black women were in the clerical and sales category. White women were more likely than black women, however, to be found especially in the professional and technical and to a lesser degree the managerial categories. Thus, even among women, significant racial inequalities in sorting across the occupational structure remain.

But it remains true that African Americans are far more likely to experience unemployment than whites (Farley 1996; Stoll 2005). As table 2.1 shows, blacks were nearly twice as likely as whites, among both men and women, to experience unemployment. The black teenage unemployment rate is particularly high at 36.5 percent and fully twice that for whites (18.4 percent). Even these numbers may understate a deepening structural unemployment problem for African Americans. Figure 2.9 reports labor force participation rates (which includes those currently employed and those still actively seeking work if unemployed) by race and by sex. Labor force participation rates have declined since the 1970s for both white and black men, though having increased for white and black women, at least through 2000. However, the black-white gap among men has grown from roughly 6 percent in 1972 to 8 percent in 2009. Furthermore, the employment to population ratio, which takes 


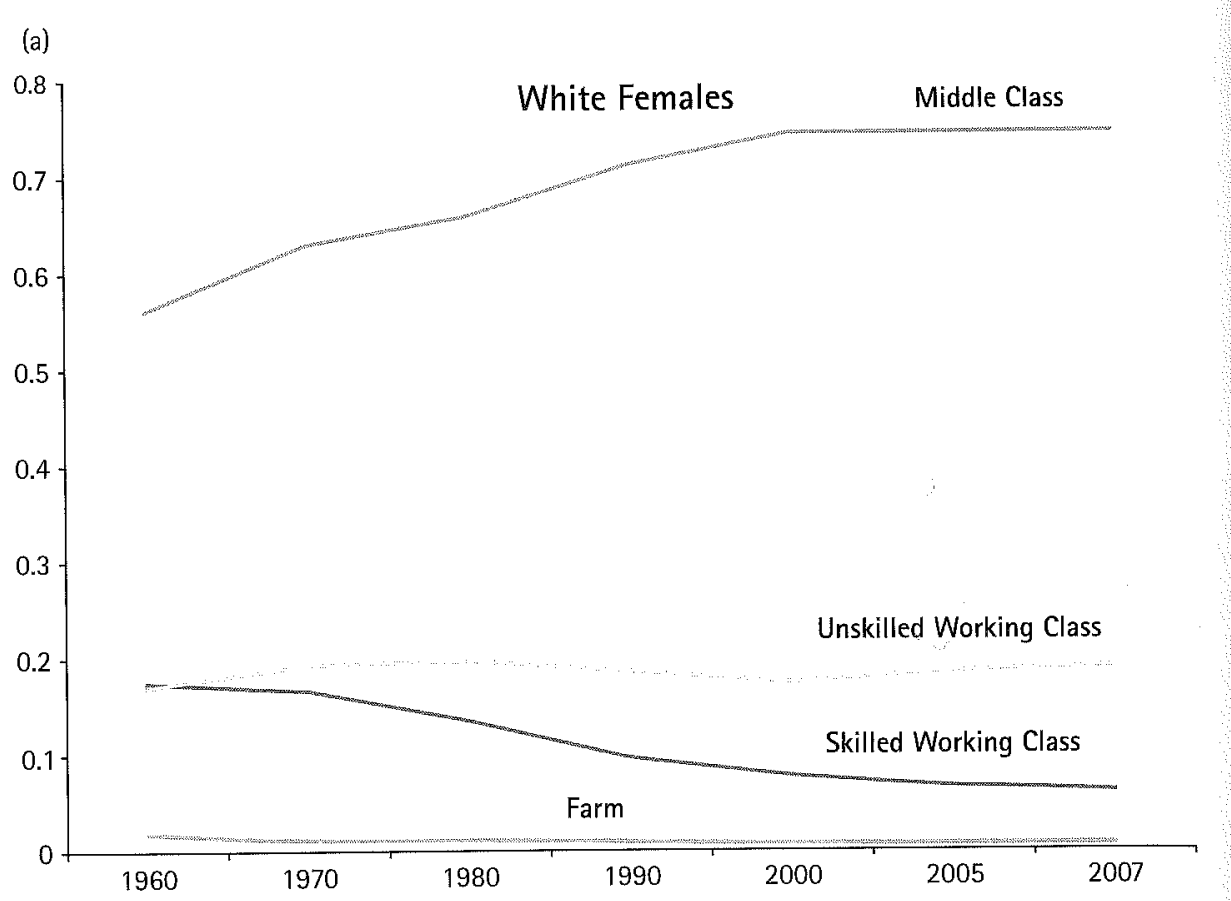

Figure 2.7a Changes in the occupational distribution for white females, 1960-2007

Source: Miriam King, Steven Ruggles, Trent Alexander, Donna Leicach, and Matthew Sobek.

Integrated Public Use Microdata Series, Current Population Survey: Version 2.0 [Machine-readable database]. Minneapolis: Minnesota Population Center.

Note: ${ }^{1}$ The occupational categories are derived from the 1950 Census Bureau occupational classification system for occupational data using the following guideline: Middle-Class = "Clerical and Sales,"

"Technical and Professional," "Managers, Officials, and Proprieters"; Skilled Working Class =

"Craftsmen," "Operatives"; Unskilled Working Class = "Service Workers," "Laborers"; Farm =

$$
\text { "Farmers," "Farm Laborers." The Universe includes the following: }
$$

1960-1970: Persons age 14+ who had worked within the previous ten years; not new workers.

1980-2000: Persons age 16+ who had worked within the previous five years; not new workers.

into account discouraged workers (those among the unemployed who have given up looking for work), also undergoes a decline for men, but particularly for black men (see figure 2.10). A gap of approximately 10 percent in 1972 widens to more than 12 percent in 2009. Moreover, these data for 2009 suggest that for the first time the black female employment to population ratio exceeds that of black men. Given that black men have shorter life expectancy than white men and are far less likely to have accumulated financial assets that allow for early retirement, these labor force participation rates and employment to population ratios must be read as a signal of serious deterioration in the labor market position of a sizeable fraction of the adult black male population.

When we turn to the question of income, something of a similar trend is evident, where black-white gaps remain substantial. According to social policy analyst Michael Stoll:

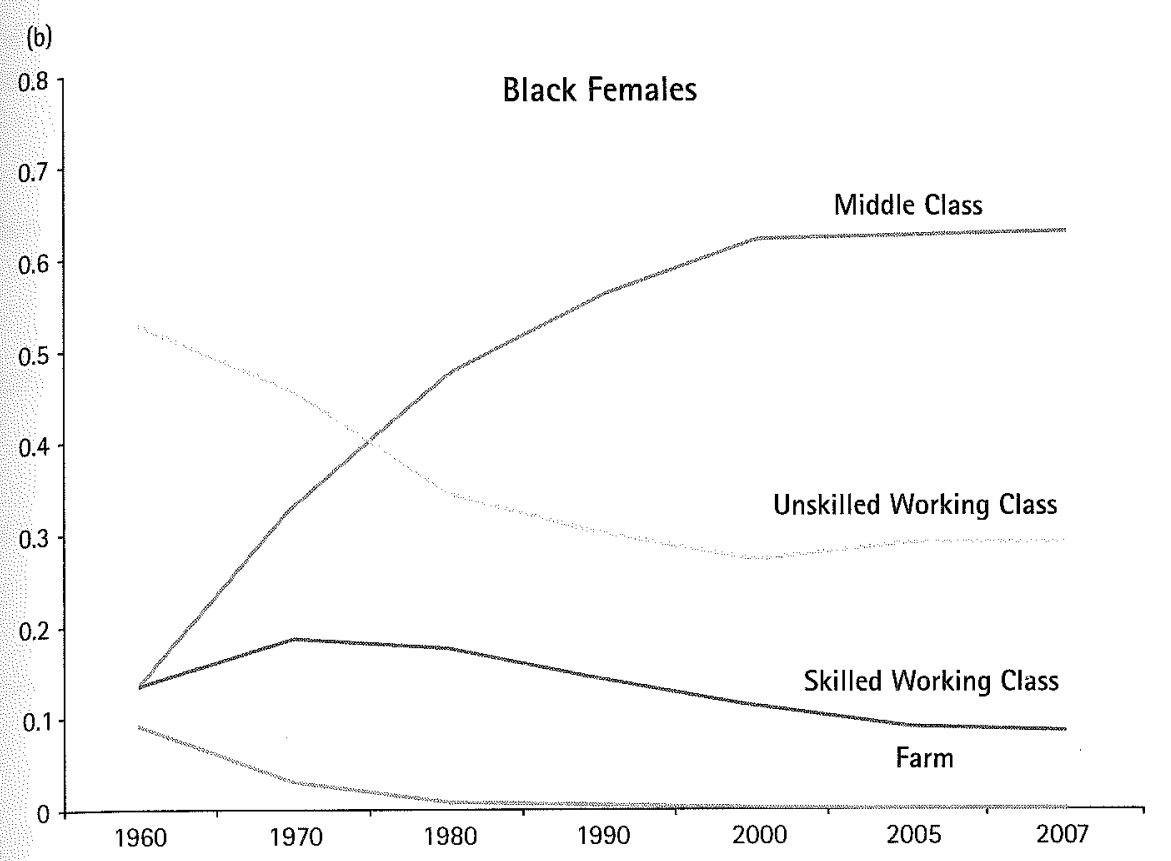

Figure 2.7b Changes in the occupational distribution for black females, 1960-2007

Source: Miriam King, Steven Ruggles, Trent Alexander, Donna Leicach, and Matthew Sobek. Integrated Public Use Microdata Series, Current Population Survey: Version 2.0 [Machine-readable database]. Minneapolis: Minnesota Population Center.

Note: ${ }^{1}$ The occupational categories are derived from the 1950 Census Bureau occupational classification system for occupational data using the following guideline: Middle-Class = "Clerical and Sales,"

"Technical and Professional," "Managers, Officials, and Proprieters"; Skilled Working Class

= "Craftsmen," "Operatives"; Unskilled Working Class = "Service Workers," "Laborers"; Farm = "Farmers," "Farm Laborers."

The Universe includes the following:

1960-1970: Persons age 14+ who had worked within the previous ten years; not new workers.

1980-2000: Persons age 16+ who had worked within the previous five years; not new workers.

relative to whites, blacks' family income levels still remained relatively low from 1980 to 2000 . Over this period, the median family income of blacks never surpassed $\$ 35,000$. To put this number in perspective, median family income in the United States in 2000 was about $\$ 52,000$, or about $\$ 17,000$ higher than the median figure for blacks. Alternatively put, blacks' median family income level of $\$ 31,000$ in 2000 was about the median family income level in the United States in 1965 (using constant 2000 dollars). Moreover, the racial gap in family income hovered consistently around \$20,000 over this period. (Stoll 2005: 391-92)

Stoll stresses that the gap in family income is increasingly dependent on household type. Ironically, the degree of black-white inequality has grown among those in married households but narrowed slightly for those in female-headed households.

Blacks continue to face a far greater risk of exposure to poverty. As table 2.1 shows, blacks were almost three times as likely as whites to be among those 


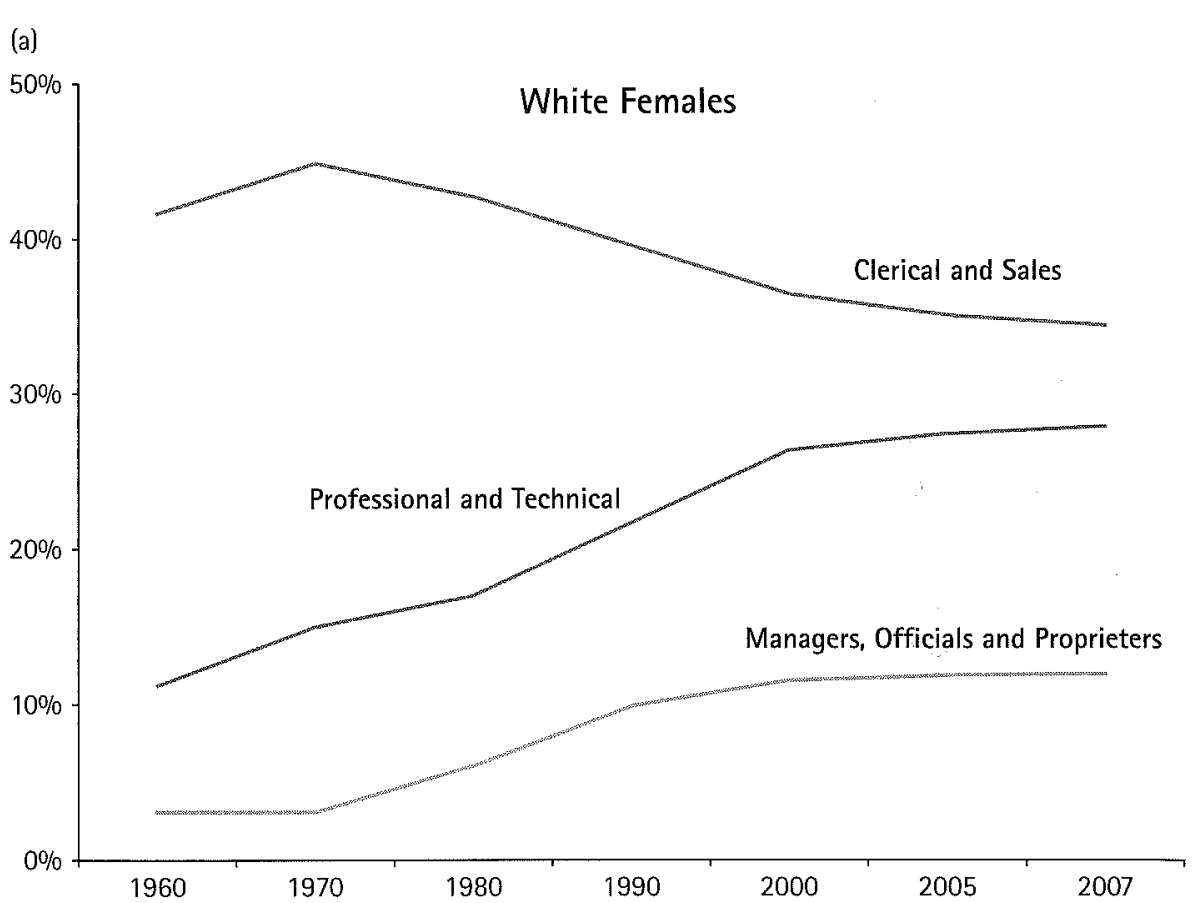

Figure 2.8a Changes in the middle-class distribution of white females, 1960-2007

Source: Miriam King, Steven Ruggles, Trent Alexander, Donna Leicach, and Matthew Sobek. Integrated Public Use Microdata Series, Current Population Survey: Version 2.o [Machine-readable database]. Minneapolis: Minnesota Population Center.

individuals living below the poverty line. Fully a third of black children (35.3 percent) were living in poverty. And black children were nearly three times as likely as white children to live in a single-parent (usually female) headed household, a factor which contributes to the risk of living in poverty. In addition, black poverty is likely to be of longer duration, deeper severity, and involve living in a community where the experience of poverty is typical rather than the exception (Wilson 1996; Farley 1996).

Differences in class background, income, and exposure to poverty all bear some relation to the educational attainments of blacks and whites. Over the long haul, there has been a significant narrowing of gaps in levels of attainment (especially) and achievement (or measured academic performance) between blacks and whites (Farley 1996; Stoll 2005). However, significant racial gaps remain. Thus, as table 2.1 shows, blacks are almost twice as likely as whites to fail to complete high school (19.9 percent versus 10.6 percent in 2009) and whites are nearly twice as likely to complete college or to go on to complete an advanced degree. Whites still outperform blacks on standard achievement tests, including the regular National Assessments of Educational Progress (see table 2.1 results for reading and math score differentials). Many factors, far beyond the scope of this essay, contribute to these gaps particularly

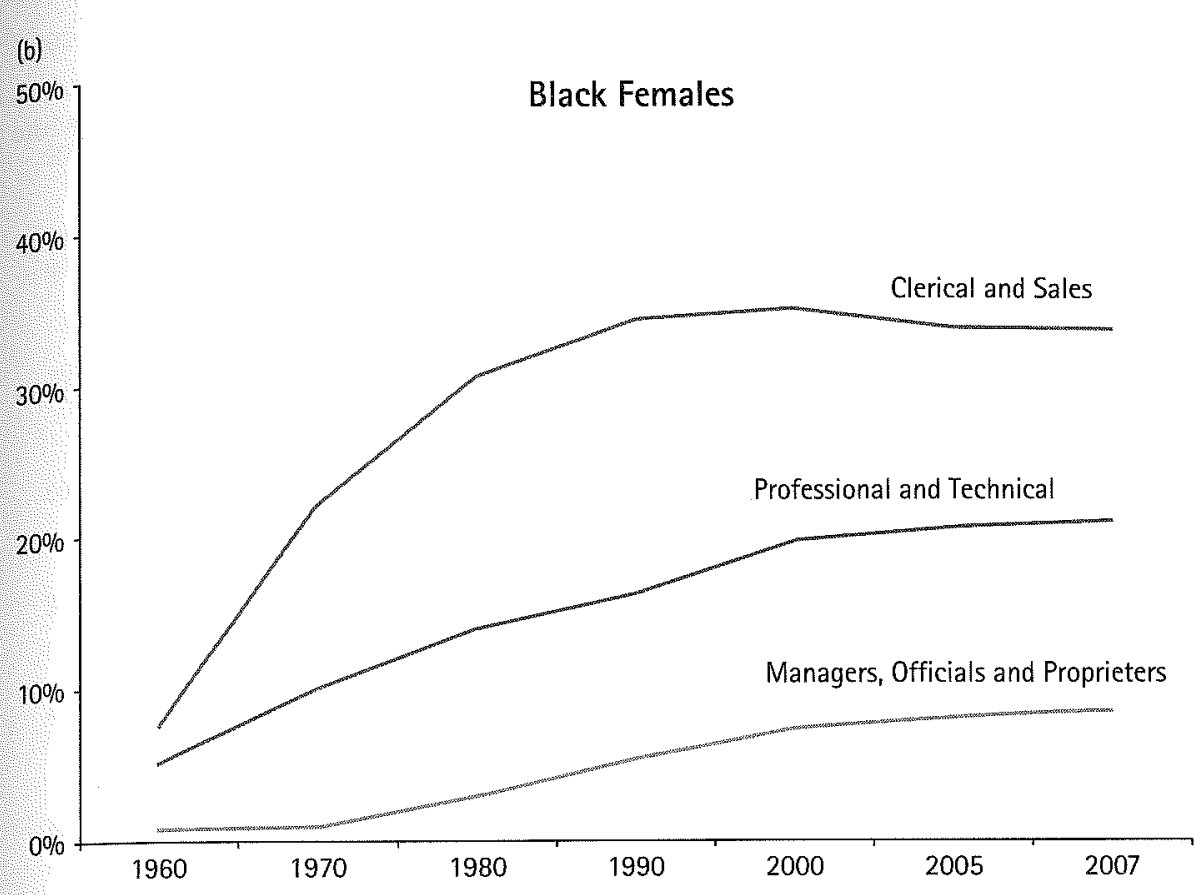

Figure 2.8b Changes in the middle-class distribution of black females, 1960-2007

Source: Miriam King, Steven Ruggles, Trent Alexander, Donna Leicach, and Matthew Sobek. Integrated Public Use Microdata Series, Current Population Survey: Version 2.0 [Machine-readable database]. Minneapolis: Minnesota Population Center.

with regard to test performance, high school graduation rates, and college attendance rates. Among those factors, however, are the availability of qualified teachers (Hammond 2004) and availability of college preparatory curriculum (see table 2.1, AP exam taking), where it is known that predominantly black schools typically fare poorly compared to what is available in predominantly white schools.

One crucial index of overall material well-being is wealth or accumulated financial assets (Oliver and Shapiro 1995). In a world where old style pensions from employers are available to a smaller and smaller fraction of the workforce, where personal savings are important to adjusting to more frequent job transitions during prime-working age years and to ultimate retirement as well as to one's capacity to maintain a lifestyle in the face of various goals (i.e., college for children) and challenges (i.e., serious illness), wealth is the critical ingredient in maintaining a standard of living. The black-white wealth gap is enormous and there are few concrete signs that this gap will narrow. According to 2007 data, the median net financial assets of white households was $\$ 15,000$ as compared to only $\$ 100$ among black households! These numbers are even more dramatic when viewed in the light of the fact that black assets are overwhelmingly composed of just two things: homes and automobiles. White wealth is more evenly spread 


\section{Table 2.1 Key National Indicators of Well-Being}

\begin{tabular}{|c|c|c|c|}
\hline & $\begin{array}{l}\text { Non-Hispanic } \\
\text { White } \\
(\%)\end{array}$ & $\begin{array}{l}\text { Black } \\
(\%)\end{array}$ & $\begin{array}{l}\text { Black/White } \\
\text { Ratio } \\
(\%)\end{array}$ \\
\hline \multicolumn{4}{|l|}{ Overall unemployment rate } \\
\hline${ }^{\circ}$ Male, 20 and older & 9.8 & 16.9 & 1.7 \\
\hline${ }^{\circ}$ Female, 20 and older & 7.4 & 11.7 & 1.6 \\
\hline Teenage unemployment, $16-19^{\mathrm{b}}$ & 18.4 & 36.5 & 2.0 \\
\hline Persons living below poverty ${ }^{c}$ & 9.2 & 25.3 & 2.8 \\
\hline Children under 18 in poverty ${ }^{c}$ & 10.8 & 35.3 & 3.3 \\
\hline Children in single-parent households $s^{c}$ & 23.0 & 65.0 & 2.8 \\
\hline \multicolumn{4}{|l|}{ Population in jail or prison ${ }^{d}$} \\
\hline Male & 0.5 & 3.2 & 6.5 \\
\hline Female & 0.1 & 0.2 & 3.0 \\
\hline \multicolumn{4}{|l|}{ Population in jail or prison ages $18-24^{d}$} \\
\hline Male & 0.7 & 4.4 & 6.2 \\
\hline Female & 0.1 & 0.2 & 2.4 \\
\hline \multicolumn{4}{|l|}{ Education, age 25 and over ${ }^{\mathrm{e}}$} \\
\hline Less than high school & 10.6 & 19.9 & 1.9 \\
\hline High school graduate or more & 89.4 & 80.1 & 0.9 \\
\hline Some college or more & 58.8 & 45.8 & 0.8 \\
\hline Bachelors degree or higher & 30.5 & 17.3 & 0.6 \\
\hline Advanced degree & 11.3 & 5.8 & 0.5 \\
\hline High school dropout rate, ages $16-24^{e}$ & 5.8 & 10.7 & 1.8 \\
\hline High school seniors taking AP exams ${ }^{f}$ & 24.3 & 13.5 & 0.6 \\
\hline NAEP average reading scores & 231 & 203 & 0.9 \\
\hline NAEP average math scores & 248 & 222 & 0.9 \\
\hline Home ownership ${ }^{\mathrm{h}}$ & 75.2 & 47.2 & 0.6 \\
\hline Median net financial assets ${ }^{i}$ & $\$ 15,000$ & $\$ 100$ & 0.01 \\
\hline \multicolumn{4}{|l|}{ Life expectancy at birth ${ }^{j}$} \\
\hline Male & 76 & 70 & 0.92 \\
\hline Female & 81 & 77 & 0.95 \\
\hline
\end{tabular}

Sources: aBureau of Labor Statistics Monthly Household Seasonally Adjusted Data November, 2009. 'Bureau of Labor Statistics Monthly Household Seasonally Adjusted Data, January, 2009. 'U.S. Census Bureau, 2005-2007 American Community Survey. ${ }^{\mathrm{d} B u r e a u}$ of Justice Statistics. Prisoners in 2007.

'U.S. Department of Education, National Center for Education Statistics. (2008). The Condition of Education 2008 (NCES 2008-031), table 23-1.

fCollege Board AP. 2008. The 5th Annual AP Report to the Nation.

sU.S. Department of Education, Institute of Education Sciences, National Center for Education Statistics, National Assessment of Educational Progress (NAEP), 2007 Mathematics Assessments.

bU.S. Census Bureau, Housing and Household Economic Statistics Division.

iElena Gouskova and Frank Stafford, Institute for Social Research, Copyright University of Michigan (April 2007). Data from Panel Study of Income Dynamics (PSID).

National Center for Health Statistics. Health, United States, 2007.

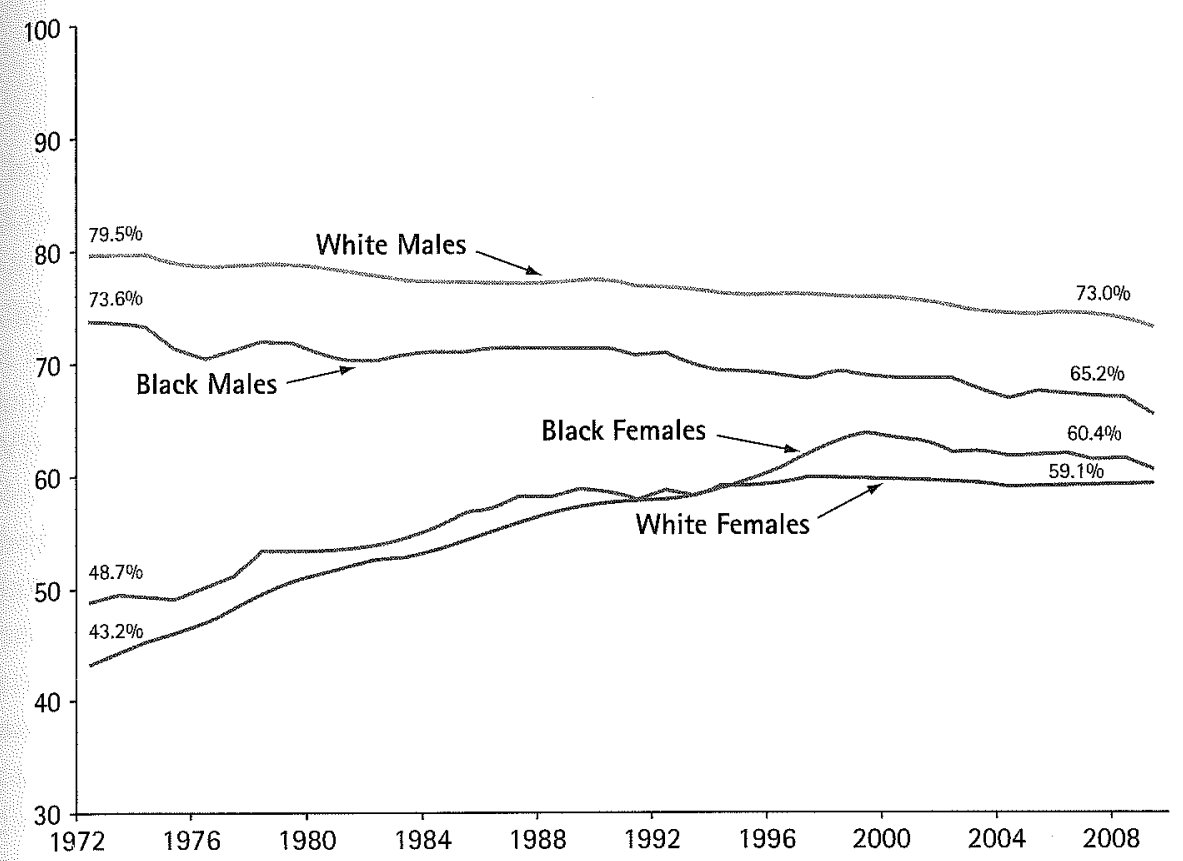

Figure 2.9 Labor force participation rates for the 16 and over population, 1972-2009 Source: U.S. Bureau of Labor Statistics, November 2009. Series: LNS11300028; LNS11300029; LNS11300031; LNS11300032. http://data.bls.gov/cgi-bin/srgate

Note: 'Yearly average. The yearly average for 2009 does not include December 2009 data.

among savings, stocks, bonds, business ownership, and other things one can convert to cash without compromising one's place of residence or mode of transportation (Oliver and Shapiro 1995). Of key importance here is a recognition that wealth is largely inherited, it is not a function of savings rates. The best research suggests that blacks and whites save at about the same rate and, in any event, income per se is a relatively weak predictor of wealth (Oliver and Shapiro 1995). Enormous wealth differentials by race, in short, are the cumulative product of centuries of a compromised claim on citizenship.

A critical dimension of the modern status of African Americans involves the problems of crime and mass incarceration (Western 2006). As table 2.1 shows, blacks are substantially more likely than whites to be in jail or prison. Indeed, among men the black to white ratio exceeds 6:1. The growth in reliance upon formal incarceration as a response to the problem of crime has had severely disproportionate effects on African Americans. Levels of incarceration in low-income black communities border on becoming the expected or normative experience for recent generations (Western 2006). Indeed, the penetration of jail and prison into the fabric of black social life is so extreme that national survey data show that even among highincome, highly educated blacks $30+$ percent have a friend or relative currently 
100

90

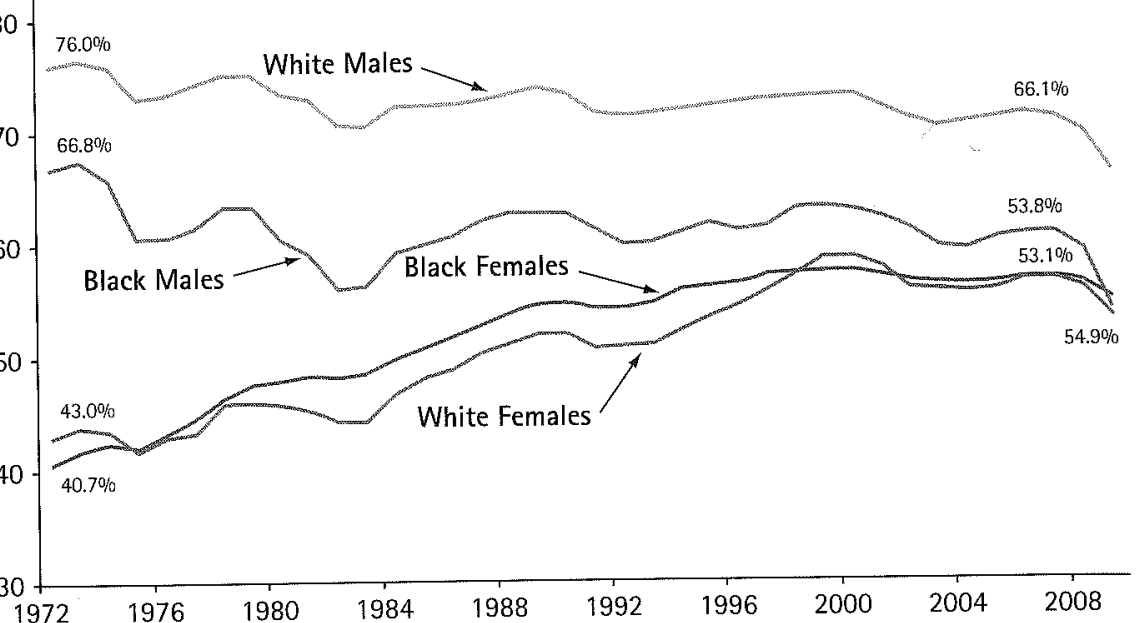

Figure 2.10 Employment-population ratio for the 16 and over population, 1972-2009

Source: U.S. Bureau of Labor Statistics, November 2009. Series: LNS11300028; LNS11300029; LNS11300031; LNS11300032. http://data.bls.gov/cgi-bin/srgate

Note: ${ }^{1}$ Yearly average. The yearly average for 2009 does not include December 2009 data. incarcerated as compared to fewer than one in ten among comparable whites (Bobo and Thompson 2010).

It is little surprise then that given blacks' lesser position across virtually all relevant socioeconomic status indicators that there would be substantial differentials in health and longevity (Williams 1999). As table 2.1 shows, black life expectancy still lags behind that for whites, though the gaps have narrowed over time, particularly among women. Approximately four years separates the life expectancy of white and black women, whereas six years separates the life expectancy of white and black men. Race differentials in health outcomes are reduced somewhat by taking into account differences in social class background and resources. However, research across an array of outcomes suggests that race differentials persist despite equating for class background factors (Williams 1999). That is, evidence is accumulating to show that the distinctive burdens of material disadvantage and segregation associated with racial inequality (Massey 2004), direct encounters with discrimination in many domains including in the provision of health care (Williams 1999), and a larger sociopolitical culture of stigmatization and racism (Geronimus and Thompson 2004) act to undermine black health outcomes.

\section{The Contributions to this Volume}

The core themes identified above are played out in more substantial historical detail in the three chapters that round out this section on the sociology of the African American citizen. Frank Samson provides a wide-ranging assessment of the strivings of African Americans for a full share of the American dream and full inclusion in the social and political landscape. Starting from the collapse of Reconstruction and running through the latter stages of New Deal reform and the immediate postWWII era, Samson traces key challenges that have constrained realization of complete economic, political, and civil status for blacks. The chapter has several clear themes. First and foremost, Samson shows that at no time were African Americans simply passive objects of oppression or a people without a history of their own making. He examines the efforts by blacks, northern and southern and across a series of key historical eras, to build communities, establish homes and businesses, raise families, educate their children, and stake a claim to all the promise of America. By dint of hard work, initiative, collective organizing, political protest, ceaseless efforts at uplift and improvement, and sheer endurance, African Americans have repeatedly, he suggests, "made a way out of no way."

Second, Samson shows the enormous contradiction between the promise and proclaimed aspirations of American democracy, on the one hand, and the repeated stalled or thwarted efforts to bring African Americans into the mainstream, on the other. This contradiction is most acute at key historical junctures, such as the collapse of Reconstruction as explicit efforts to protect the rights of blacks are slowly, inexorably rolled back, compromised, and denied. Or, even more pointedly, at those points when blacks served as troops, be it in the Spanish-American War, WWI, or WWII, risking their lives in service to a nation not yet ready to embrace them as equals. Nothing drives home this gap between promise and reality, between the claims for American democracy and the actual experiences and circumstances of African American life, than the historic waves of destructive violence blacks faced in different eras and parts of the country. Blacks encountered much more than discourteous treatment, closed doors, and blocked job opportunities. From the reign of Ku Klux Klan terror and brutal lynchings characteristic of the establishment of the Jim Crow regime of the South, through the riots and mob attacks directed at blacks migrating to industrial centers of the Midwest and other parts of the North during the early 1900 s through the start of WWII, blacks often faced a chilling level of destructive violence.

Third, and of crucial analytical importance, there is no magic hand of institutional arrangements that thwarted black aspirations. There was instead active, deliberate, and often systematic antiblack bias in many different places, taking many different specific forms, in many different contexts and situations. If there is a persistent or constant factor in Samson's analysis, it is a recognition of the social force of popular acceptance by many white Americans of racist ideas, beliefs, and expectations that viewed blacks as not properly entitled to a full and fair share of all those 
opportunities, resources, experiences, and statuses enjoyed by their white counterparts.

But who exactly is black, who is white, and why did such categories come to assume such decisive force in the development of American society? In order to shed light on these questions, Victor Thompson interrogates the very concept and idea of race. He explores how the concept of race has both taken shape with and influenced the development of American sociopolitical institutions. His argument is set in the context, first, of the debates over whether we as a society must continue to recognize race (if for no other reason than to address inequalities long associated with it) or if we should eschew all attention to race (because races do not actually exist and because reference to the concept only serves to reinforce social divisions and inequalities that are the historical legacy of invoking race-based distinctions). Closely attendant to this challenge of whether to be race-conscious or color blind is, second, a concern with just how fundamental and intractable the influence of notions of race is within American institutions and culture.

Thompson adopts a clearly constructivist stance on race, seeing it as a socially created, historically emergent, and contingent notion. At the same time, Thompson shows how nascent ideas of race shaped early colonial law and practice as well as the framing and adoption of the U.S. Constitution. Indeed, he carefully parses and debunks claims that the U.S. Constitution is devoid of concern with race. Thompson also shows how the collapse of Reconstruction and emergence of the Jim Crow regime helped to solidify the American norm of hypodescent or the one-drop rule whereby any black ancestry rendered one black, culturally as well as in the official judgment of the state. Thompson also makes it clear how political currents and trends in social scientific research (e.g., the rise of the eugenics movement early in the twentieth century) influenced and helped to solidify racial categories and thinking.

Furthermore, Thompson shows that African Americans participated to a degree in debates on how to conceptualize race. Some of this, of course, took the form of intellectual and social scientific discourse. But more centrally it was tied to more overtly political projects, notions of group membership, and especially to judgments about whether America could ever be a place of full economic, political, and civil status for blacks. To wit, his tracing of legal and governmental use of racial categories is informed by considerations of debates between the likes of Fredrick Douglass and Alexander Crummel, Booker T. Washington and W. E. B. Du Bois, and Martin Luther King, Jr. and Malcolm X.

In general, Thompson suggests race is a notion deeply embedded in the American institutional and cultural fabric. Specifically, he concludes by suggesting that even in the wake of recent debates over Census measurement procedures, and despite a variety of signs of movement and fluidity in thinking about race, at least a black versus nonblack divide remains strong. He reviews the recent emergence of a more potent mixed and multiracial political movement and its impact on the official government conception and measurement of race. None of these developments point to the disappearance of racialized thinking or of a racialized social order.
The final contribution from Maria Krysan directly examines what sociological research can tell us about the changing racial attitudes of white and black Americans. She provides a comprehensive, detailed, and rich analysis of what both survey-based and more qualitative assessments of change in race attitudes tell us. Her assessment is built around four key historical eras, which span WWII, the Civil Rights Movement, the Black Power Movement, and the more contemporary period. Within each era, as far as available data allow (and the data for African Americans, particularly from surveys, are far sparser than exist with regard to whites), she compares blacks and whites and examines differences between Southerners and Northerners. In each time period, she endeavors to assess racial beliefs or stereotypes and ideas about the characteristics of racial groups and their members; racial principles or the broad ideals that guide black-white relations, from the segregationist and openly discriminatory norms of the Jim Crow era to the integrationist and nondiscriminatory ethos of the post civil rights era; social distance feelings or willingness to engage in interracial contact and association across numerous domains of life; and racial conflict beliefs or perceptions about the extent to which white and black objectives and interests mesh or collide.

Her analysis is framed in terms of two key conceptual underpinnings or themes. The first is rooted in Myrdal's notion of different "rank orders of discrimination" that organize the racial thinking of white and black Americans. This rank order of discrimination exhibits a durable influence on the configuration of attitudes and beliefs for both blacks and whites she finds. Accordingly, at the top, center-most position on the rank order of discrimination is what Myrdal (1944) termed the "anti-amalgamation doctrine": a strict prohibition against interracial sexual relations and marriage, particularly as it might involve white women and black men. This was followed, in order, by a rejection of "social equality" (close association in other public and informal settings such as social clubs or restaurants); a call for segregation and discrimination in access to schools, public transportation, and the like; political disenfranchisement; discrimination within the legal system and by public officials; and finally discrimination in access to other valued social goods, such as jobs, credit, welfare, and so on. For blacks, according to Myrdal, the rank order of discrimination was very nearly the exact opposite that for whites. First and foremost, blacks wanted equal access to material things like employment and jobs, credit, and other government benefits. Then, for blacks, freedom from discrimination by government in application of the law and enjoyment of the basic right to vote came next. And various forms of social contact with whites were much lower priorities for blacks and while not rejecting interracial marriage, it was not a key aspiration of the black community as such.

Krysan's second conceptual underpinning involves a tentative framing of the changes in race relations and attendant attitudes and beliefs as involving a movement from a clear-cut caste system to a putatively color-blind social order. But here she stresses there is strong evidence of a new or reconstituted racism at work in more recent years; a form of racism that elsewhere I have labeled laissez-faire racism (Bobo et al. 1997). Accordingly: 
Laissez-Faire racism involves persistent negative stereotyping of African

Americans, a tendency to blame blacks themselves for the black-white gap in socioeconomic status, and resistance to meaningful policy efforts to ameliorate U.S. racist social conditions and institutions. It represents a critical new stage in American racism. As structures of racial oppression became less formal, as the power resources available to black communities grew and were effectively deployed, as other cultural trends paved the way for an assault on notions of biologically ranked "races," the stage was set for displacing Jim Crow racism and erecting something different in its place. (Bobo 2004: 17).

The dissipation of the attitudes undergirding the old Jim Crow caste order notwithstanding, Krysan carries forward a modest note of ironic skepticism, originally expressed by Myrdal, that white America may never live up to its principles in full measure where blacks are concerned.

\section{Conclusion}

Du Bois opened the first chapter of his immortal The Souls of Black Folk by drawing attention to a question: "How does it feel to be a problem?" Despite enormous change in the economic, political, and civil status of African Americans, the poignancy and indeed nagging frustration of $\mathrm{Du}$ Bois's question endures. The African American path to full citizenship, great strides notwithstanding, remains partial and incomplete.

To be sure, I offer this conclusion mindful that much of the evidence reviewed above and in the supporting chapters of this volume, can be read as charting a vast improvement in the material conditions, political rights, and broader civil status of African Americans. As distinguished Harvard sociologist Orlando Patterson put it "the achievements of the American people over the past half century in reducing racial prejudice and discrimination and in improving the socioeconomic and political condition of Afro-Americans are nothing short of astonishing" (1997: 15). So great have been the changes that Patterson goes on to declare, "Viewed from the perspective of comparative history and sociology, it can be said unconditionally, that the changes that have taken place in the United States over the past fifty years are unparalleled in the history of minority-majority relations" (1997: 15-16). Others share the view that the nation has made enormous progress. Thus, Abigail and Stephan Thernstrom asserted that "the foundation of progress for many blacks is no longer fragile. Progress is real and solid" (1997: 535).

Indeed, in the wake of the election of the nation's first African American President in Barack Obama, we have seen a torrent of discussion about transcending race and arrival at a post-racial moment (Bobo 2011). At the same time, there remain numerous indicators of black-white inequality, so much so that many scholars still speak of a deep and hopelessly obdurate racial divide. How can such profoundly contradictory circumstances be resolved? One answer is to separate the known facts from the larger inferences or interpretations drawn from them. That is, for example, election of a black president does not presuppose or require an end to the problem of racism and black-white inequality and the persistence of racism and inequality does make election of a black president impossible.

The problem may lie in the tendency of analysts to read too much into some very particular outcome or event as opposed to focusing on systemic or fundamental achievements. As sage observer John Hope Franklin put it in the conclusion to his autobiography:

All too often we tend to take notice of our progress toward economic justice and equality by pointing to the few African Americans who have reached the top in the communications industry and to the very small numbers in the powerful investment firms and merchandise establishments. At this point it is well to remember our history. In the antebellum years, when the vast majority of black people were in slavery, some blacks were free and a few even held slaves. In the post-Reconstruction years, there were a few powerful black educators and even a few well-to-do blacks in business and the professions. But they were not a portent or even a promise of a brighter future. We are compelled to ask if these were the exceptions that prove the rule. Might such variations from the norm serve the purpose of ensuring that there is sufficient "sway" in America's still-racist structure to provide the "give" necessary to protect that structure against the winds that could, without that "give," destroy it? (Franklin 2005: 379)

Franklin's view treats blacks' gains as quite real but also as delimited, necessarily set within the bounds of an American racial system that on the whole continues to relegate blacks to largely secondary and disadvantaged status.

Alternatively, Patterson has argued that it makes more sense to regard the circumstances of African Americans as complicated and contradictory if not paradoxical rather than as locked into inescapable marginality. Even within this paradox, however, some analysts like Patterson prefer to see the deep, fundamental underlining dynamic and trajectory as an optimistic one. ${ }^{13}$ He suggests:

the present condition of Afro-America is itself paradoxical, and the perceptions of this condition and the attempts to understand it are further riddled with paradoxes and contradictions. Observing this is like watching the foreplay of two octopuses through the distorting window of a glass-bottom boat. They appear to be consuming each other when, in fact, they are really trying to connect.

(Patterson 1997: 16)

This sort of paradoxical but optimistic view of race relations certainly has some basis in the available body of research.

It is instructive to set these competing interpretative tendencies or positions within the context of what we know about the recent thinking of the mass of average African Americans themselves about the racial divide, particularly after the election of Obama. I conducted a large national survey of blacks in 2009 that repeated three previously used measures of the extent of racialized thinking and identity 
among black Americans (Bobo and Simmons 2009). These results indicate that al though few embrace the most pessimistic assessments of the racial divide, comparatively few African Americans are ready to conclude that we've arrived at "the end of the black American narrative" (Johnson 2008).

Given all the patterns addressed above, it comes as little surprise that most African Americans still hold highly racialized social identities. As figure 2.11 shows, in a 2009 national survey of blacks, more than a third (35.5 percent) said that "what generally happens to black people in this country" would have "a lot" to do with what would happen in their own lives. When first asked of blacks in 1984, 31 percent gave this response (see Dawson 1994: 78). Another third (33.6 percent) in 2009 said there was "some" connection between their own life and that of black people generally, virtually identical to the 32 percent who said so in 1984 . There has been correspondingly little change in the percentage of blacks seeing little or no connection between their own fate as individuals and that of blacks as group comparing 2009 (30.8 percent) to 1984 (37.0 percent). Here it is important to stress that this sort of "common fate identity" is a far more significant form of group identification than that tapped by the Census-style racial identity question. The former has been shown to influence and structure a range of political outlooks and behavior (Dawson 1994 and 2001). It is one thing to merely classify one's self into a particular category, it is something else and a good deal more telling to see membership in a particular social category as substantially shaping one's fate in life.

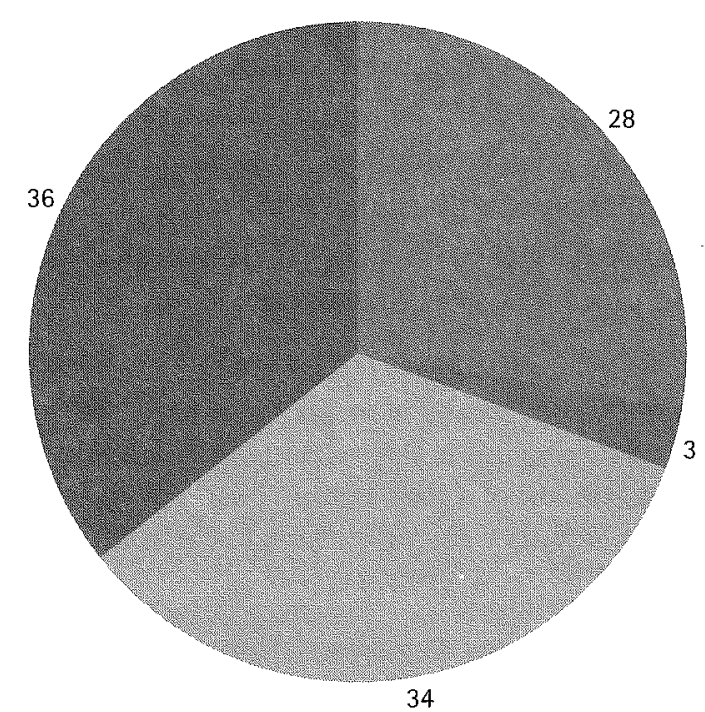

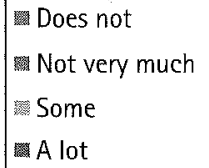

Figure 2.11 Blacks' belief that what happens to other blacks affects one's own life (Note: Figures may not sum to exactly $100 \%$ due to rounding.) Source: Race Cues, Attitudes, and Punitiveness Survey (2009)

Note: "Do you think what happens generally to black people/African Americans in this country wil have something to do with what happens in your life?" (yes/no) If yes, "Will it affect you a lot, some, or not very much?"
A perception of significant racialization of social life emerges when blacks are asked to assess the relative economic standing of blacks and whites. That is, most blacks still perceive clear black economic disadvantage relative to whites. The 2009 national survey data presented in figure 2.12 reveal almost one-third ( 31.8 percent) of blacks saying that whites are much better off financially than blacks, a number largely unchanged from 1984 ( 35 percent).

African Americans are more internally divided over assessments of the general status and trajectory of progress toward racial equality and justice. As figure 2.13 shows, fewer than one in five blacks believe that we have already achieved racial equality. But more than a third ( 36.2 percent) endorse the idea that we will soon achieve racial equality, where the meaning of the term "soon" is unspecified. Still, this leaves a third ( 33.5 percent) rejecting the idea that racial equality will be achieved. during their own lifetime and another 12.9 percent expressing the view that equality will never be achieved. The assessment of where the United States stands in race relations is far rosier among white Americans. There the data show that nearly two out of three white American say that we already "have achieved racial equality." Whites are thus three times more likely than blacks to claim we've basically arrived at equality of the races. What is more, this is the solid majority view among whites, but is true for fewer than one in five blacks. The two groups, on this question then, are very nearly worlds apart.

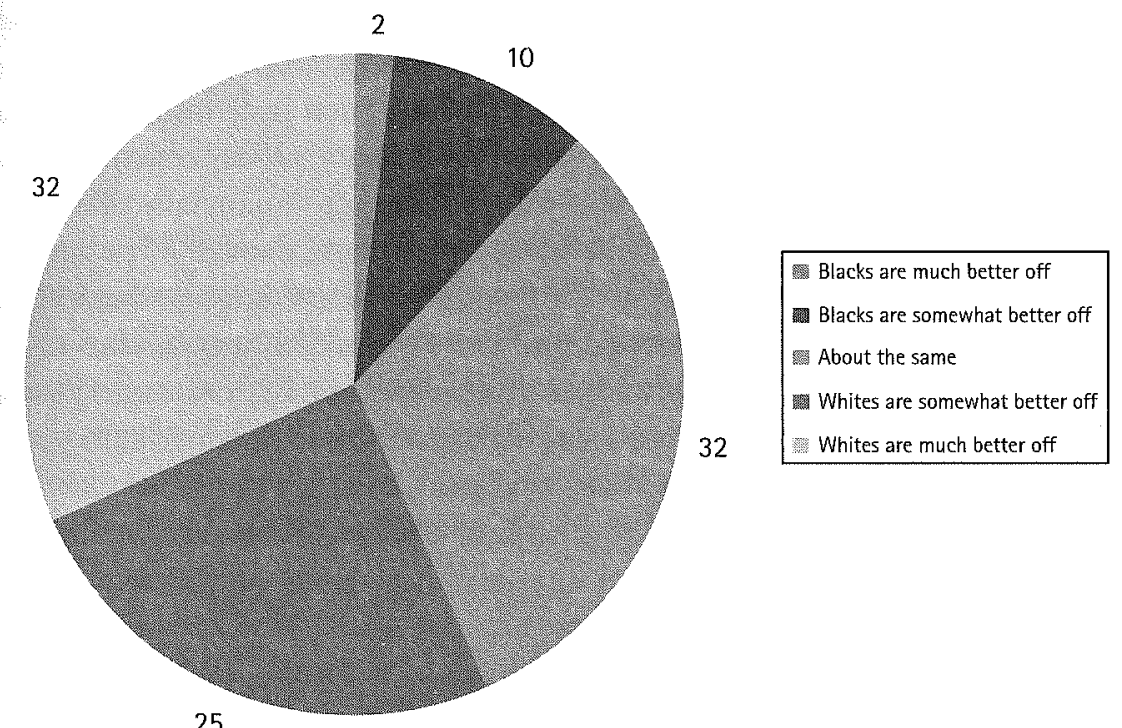

Figure 2.12 Blacks' perception of blacks economic position relative to whites (Note: Figures may not sum to exactly $100 \%$ due to rounding.) Source: Race Cues, Attitudes, and Punitiveness Survey (2009)

Note: "On the whole, would you say that the economic position of blacks is better, about the same, or worse than that of whites?" If better, "Would you say it is somewhat better or much better than that of whites?" If worse, "Would you say it is somewhat worse or much worse than that of whites?" 


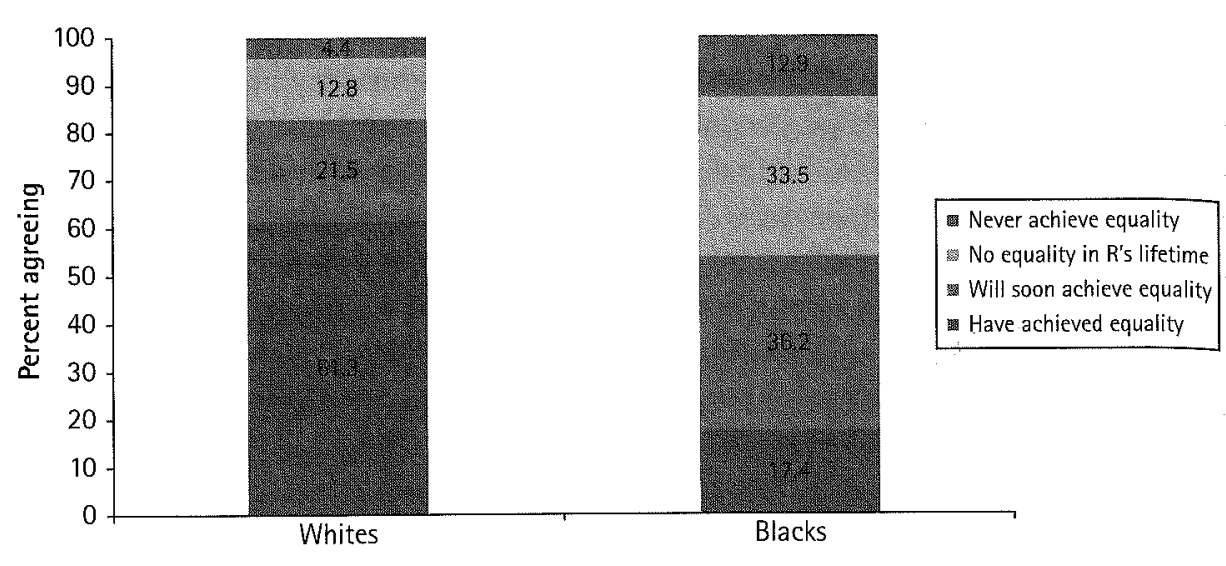

Figure 2.13 Beliefs about when racial equality will be achieved

Source: Race Cues, Attitudes, and Punitiveness Survey (2009)

Note: "Do you think that blacks have achieved racial equality, will soon achieve racial equality, will not achieve racial equality in your lifetime, or will never achieve racial equality?"

Response to these three questions can be thought of as arraying individuals on a broad continuum assessing the degree of perceived racialization of American society. At one end of this continuum, low perceived racialization individuals believe that race no longer defines what one is likely to achieve as an individual, that blacks have arrived at rough economic parity with whites, and that full racial equality is a near-term or already accomplished fact. At the other end of the spectrum are those individuals high in perceived racialization of society. Such individuals see at least "some" or "a lot" of connection between one's race and one's likely outcomes in life, perceive whites as at least "somewhat" to "much better off" financially than blacks, and do not expect racial equality to be achieved in their own lifetime or ever. ${ }^{14}$ Figure 2.14 shows the distribution on this Perceived Racialization Index measure. The first thing to appreciate is that, despite the simple dichotomization of each component item of the index we employed, the bulk of black Americans fall somewhere in the middle. That is, among the lay black public both a consistent, strongly deracialized view of life in America and a consistent, strongly racialized view of life in America are minority positions. The great bulk of black Americans report seeing and experiencing a more complicated circumstance. However, having said this, more than one in four blacks do express the more consistently highly racialized view.

What we do know about the social sources of the degree of perceived racialization of society? Figure 2.15 presents the relationship between the Perceived Racialization Index and respondents' sex, income, age cohort, and level of education. Men express slightly higher perceived racialization than do women. There is a 14 percentage point difference between low income and high income individuals, with the higher income individuals expressing the greatest perceived racialization. The oldest age group, those who came of age during the civil rights movement years or earlier,

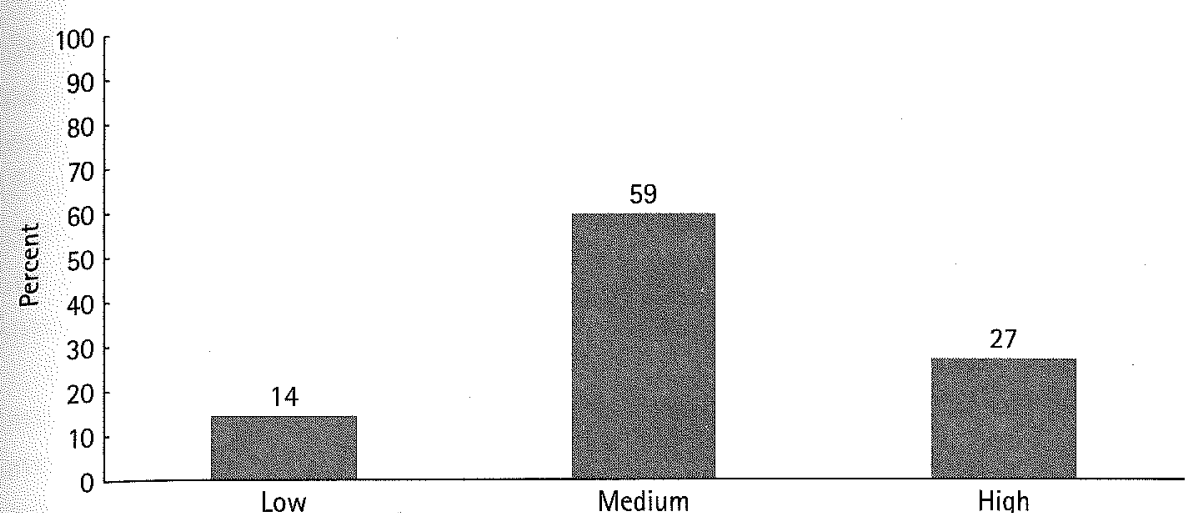

Low

Medium

High

Figure 2.14 Blacks' scores on the Perceived Racialization Index

Source: Race Cues, Attitudes, and Punitiveness Survey (2009) Note: Low $=101 ;$ Medium $=443 ;$ High $=203$

Index is calculated by first dichotomizing the shared fate, economic inequality, and racial equality items. Scores of o on shared fate represent responses of "not very much" or "does not," while scores of 1 represent responses of "a lot" or "some." Scores of o on economics inequality represent responses of "blacks are much better off," "blacks are somewhat better off" or "about the same," while scores of 1 represent responses of "whites are somewhat better off" or "whites are much better off." Scores of o on racial equality represent responses of "have achieved racial equality" or "will soon achieve racial equality," while scores of 1 represent responses of "no equality in lifetime" or "never achieve equality." These three o-1 variables are then summed into the index, which ranges from 0 to 3 , where higher values indicate greater racialization. The index is finally recoded into three categories, where "low" represents those scoring o, "medium" represents those scoring 1-2, and "high" represents those scoring 3 .

express the highest degree of perceived racialization (34 percent), whereas the youngest cohort, the post-Reagan era group, expressed the lowest (18 percent), for a difference of 16 percentage points. The strongest polarization of views occurs by levels of education where those with a high school education or less are the least likely to express a racialized view of society (19 percent) as compared to those who completed college ( 38 percent), for a difference of 19 percentage points. Interestingly, virtually no well-educated blacks (only 6 percent) fall in the low perceived racialization category.

We also conducted a fuller multivariate analysis (not shown here) where scores on the Perceived Racialization Index were predicted by region of the country (South versus non-South), degree of racial segregation, sex, income, age, and education. Only three factors yielded significant effects in these models: age, income, and education. Consistent with the results of figure 2.15 , the multivariate results indicate that older blacks, high income blacks, and especially the most highly educated blacks express the highest levels of perceived racialization of society.

One more optimistic reading of these results is that younger blacks are moving away from a strongly racialized view of social life. If so, then those forecasting a 


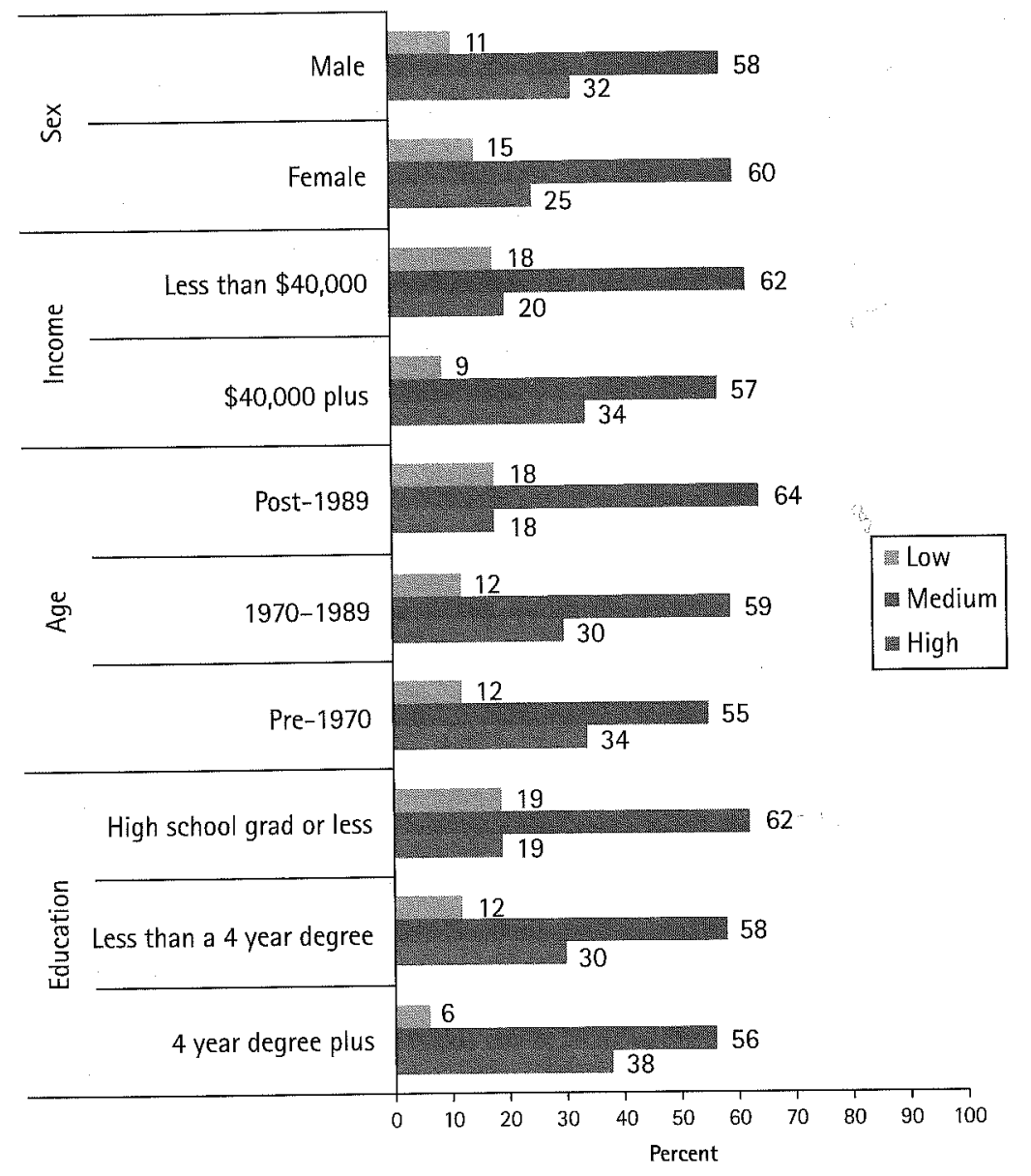

Figure 2.15 Blacks' scores on the Perceived Racialization Index across respondent characteristics (Note: Figures may not sum to exactly $100 \%$ due to rounding.) Source: Race Cues, Attitudes, and Punitiveness Survey (2009)

Note: Age: "Post-1989" includes respondents who turned 18 years of age after 1989 (aged 18-37 in 2009) "1970-1989" includes respondents who reached adulthood between those years (aged 38-57 in 2009). "Pre-1970" includes respondents who reach adulthood before 1970 (aged 58 or older in 2009). Education: "Less than a 4-year degree" includes responses of "some college" and "2-year degree." "4-year degree plus" includes "4-year degree" and "post-grad.

gradual weakening of racialized identities (and one presumes of related social experiences and conditions as well) can take heart in this aspect of the results. On the basis of cross-sectional data we cannot separate distinctive cohort effects from those of aging per se. Hence, it is entirely possible that as the younger age group moves out into a broader array of adult social roles and experiences across the life course they might come to resemble more the older generation of respondents in their outlooks. ${ }^{15}$ A more cautious reading suggests that those African Americans whose social class attributes-those with high incomes and the highly educated-most often embed them in regular interaction (and arguably competition) with whites and in white social spaces are those most likely to read their experiences as still deeply race-inflected. ${ }^{16}$ At a minimum, these data make clear that a large fraction of African Americans, particularly those most materially secure and likely to be among politically and culturally influential elites, remain a long distance from embracing a view that race no longer matters in their own lives, that of the larger community, or American society as a whole.

It seems only fair to set a high and exacting standard for judging whether blacks have or ever will arrive at full citizenship in the United States. African Americans have fought and died in every war ever waged by this nation, including its founding revolutionary war. Blacks have been a part, if not in fact a defining part, of each major moment in defining the nation's institutions and character from the drafting of the Constitution, through the devastation of the Civil War, to the great waves of reform attendant to New Deal social provision and later the Great Society/War on Poverty eras. Furthermore, times of major progress for blacks typically required overt action and demand on the part of blacks and their allies (Klinkner and Smith 1999), not the unbidden extension of a welcoming hand. In this context, for the observer and analyst to set a lower standard for measuring black progress than full, unmarked, and complete inclusion seems an unduly generous position.

Thus, we return to Du Bois's inquiry: How does it feel to be a problem? Indeed, not just a problem but a deeply vexing conundrum that seemingly has no certain happy resolution? As historian John Hope Franklin put it in the epigraph that opens this essay, the specter of race still hovers over the land. To be sure, much has changed for the better. Blacks in the United States enjoy a material and economic status, social mobility, political incorporation, and cultural embrace that was unimaginable a century ago. At the same time, there is little evidence that basic racial categories have broken down, on virtually any indicator of economic standing you choose blacks lag significantly behind whites, and problems of negative attitudes and beliefs, racism, and discrimination are alive if now manifested in less consistent and pervasive form than in the past (Bobo and Charles 2009). African Americans have traveled a hard and demanding road to citizenship. There are no doubt bends and turns in the road ahead, for the journey is long and not yet complete.

\section{NOTES}

I wish to thank Alicia Simmons for her skillful research assistance in the preparation of this manuscript.

1. Takaki (1987) offers a searching critique of Glazer's formulation. In particular, he draws attention to slavery, the Naturalization Law of 1790 that offered citizenship only to "free white" immigrants, the recognition of numerous Native American tribes, the interment of Japanese Americans during WWII, and the sharp distinction long made in the United States between differences understood as mainly ethnic in character as opposed to those construed as "racial" in character. 
2. Dawson (2001) provides a probing social scientific read on varieties of black nationalist thought. Shelby (2005), likewise, gives a careful and probing philosophical assessment of a range of black nationalist thought.

3. In a fashion this analysis presages Du Bois's later thinking on the features, potential, and obligations of "the talented tenth."

4. Many subsequent analysts would address frictions across the black class structure, especially Frazier (1957). Distance and tension between middle-class blacks and those of working-class or lower background figured in a number of more recent assessments as well (see Landry 1987; Lacy 2007; Pattillo 2007).

5. This concern with structure versus culture in accounting for racial inequality was the primary subject of William Julius Wilson's most recent book More Than Just Race, where he declares, "in terms of major effects on immediate group social outcomes and racial stratification, structure trumps culture. Nevertheless, I firmly believe that to apply these explanations totally separately, without any attempt to show how they interact, is indeed a mistake" (Wilson 2009: 21). But Wilson goes on to emphasize the seductions and risks of culture focused analyses, arguing that "the use of a cultural argument, however, is not without peril. Anyone who wished to understand American society must be aware that explanations focusing on the cultural traits of inner city residents are likely to draw far more attention from policy makers and the general public than structural explanations will It is an unavoidable fact that Americans tend to deemphasize the structural origins and social significance of poverty and welfare. In other words, the popular view is that people are poor or on welfare because of their own personal shortcomings" (Wilson 2009: 43).

6. Some prominent figures vigorously criticized Myrdal's moral dilemma framework. Noted black writer and commentary Ralph Ellison was one such critic (Ellison 1964).

7. Katz (1991) provides one of the best summaries of the logic and implications of Allport's basic theoretical framework. He also places Allport's model in the context of Myrdal moral dilemma argument.

8. Ensuing generations of research provide much empirical support for key elements of the contact hypothesis (Pettigrew 1998), though a number of situational contingencies need to be taken into account.

9. Thus, Lieberson writes, "the legacy-of-slavery argument is similar to that generated in the emphasis on norms and values, except that in this case the origins of such

alleged characteristics are traced specifically to the impact of slavery. Accordingly, one can repeat here that the available hard evidence leads one to conclude that at the outset the disposition of blacks was not at all less promising than was the disposition of new Europeans" (1980: 365)

10. Prominent among these right-wing analysts were Charles Murray (1984) and Lawrence Mead (1992). These works essentially faulted cultural and behavioral deficiencies as key roots of poverty and black disadvantage. They also credited permissive and overly generous social policy provision as contributing to poverty and attendant social problems of family breakdown, juvenile delinquency, and crime.

11. Stereotypes have long played a role in shaping the status of blacks and often transform or are molded to the circumstances and needs of dominant social groups. In particular, the perception of blacks as lacking key behavioral and value orientations ostensibly valued by whites, especially in terms of work ethic, responsibility, decorum, native intelligence, and the like have been long-standing features of antiblack ideologies (Johnson 1949; Takaki 1970; Bobo 1988). Bobo (2001) provides a review and conceptual backround on how stereotypes fit into other modern examinations of racial attitudes and relations.

12. McDermott and Samson (2005) provided a wide-ranging review of the multidisciplinary production of scholarship on whiteness.

13. Nathan Glazer makes a similar case for optimism in his assessment of the multicultural education movement. He suggests that while not ignoring a history of discrimination and prejudice and the contemporary circumstances of inequality, educators would be wise to focus on points of success. Glazer wrote, "There is a question of practical utility here. For their own good, their own progress, I believe that it would be better for young blacks to believe that there has been improvement in their situation, that their opportunities are greater than before, rather than the reverse. This is aside from the fact that the evidence I believe overwhelmingly supports this conclusion" (Glazer 1997: 47).

14. The three questions are all positively intercorrelated, though in no sense constitut strong single dimension. The summary index involves cut points on each component item that are necessarily somewhat arbitrary though we believe intuitively appealing and useful distinctions.

15. The research of ethnographer Alford Young (2004) is instructive in this regard. His tudy of low-income black men found that those poor blacks who rarely or never ventured outside the ghetto community were the least likely to think about race and the least likely to do so in more politicized terms. Those blacks who had experience, either through school or especially work or employment experience outside the ghetto, adopted far more racialized and politicized outlooks. He suggests that as social experiences bring one into direct contact with white individuals and into a variety of white-dominated social spaces the degree of racialized thinking intensifies.

16. Chong and Kim (2006) bring quite compelling national survey data to bear on this point. They find, in a comparative analysis of the experiences of African Americans, Latinos, and Asians that in general higher status individuals adopt less racialized views of society unless they continue to encounter discriminatory experiences. They conclude that "an important lesson from this analysis is that support for racial and ethnic group interest is strengthened by the failure of society to provide equality of opportunity and weakened by favorable experiences of economic status" (Chong and Kim 2006: 348, emphasis in original)

\section{REFERENCES}

Adorno, T. W., Else Frenkel-Brunswik, Daniel J. Levinson, and R. Nevitt Sanford. 1950. The Authoritarian Personality. New York: Norton.

Allport, Gordon W. 1954. The Nature of Prejudice. Reading, Mass.: Addison Wesley.

Bean, Frank D., Cynthia Feliciano, Jennifer Lee, and Jennifer van Hook. 2009. "The New U.S. Immigrants: How Do They Affect Our Understanding of the African American Experience?" Annals of the American Academy of Political and Social Science 621: 202-20.

Bell, Derrick. 1992. Faces at the Bottom of the Well: The Permanence of Racism. New York: Basic Books.

Blalock, Hubert M. 1967. Toward a Theory of Minority-Group Relations. New York: Wiley. Blauner, Robert. 1972. Racial Oppression in America. New York: Harper \& Row. 
Bobo, Lawrence D. 1988. "Group Conflict, Prejudice, and the Paradox of Contemporary Racial Attitudes." Pp. 85-116 in Eliminating Racism: Profiles in Controversy, edited by P. A. Katz and D. A. Taylor. New York: Plenum.

. 2001. "Racial Attitudes and Relations at the Close of the Twentieth Century." Pp. 264-301 in America Becoming: Racial Trends and Their Consequences, Vol. 1, edited by N. J. Smelser, W. J. Wilson, and F. Mitchell. Washington, DC: National Academy Press. - 2004. "Inequalities that Endure?: Racial Ideology, American Politics, and the Peculiar Role of the Social Sciences." Pp. 13-42 in The Changing Terrain of Race and Ethnicity, edited by M. Krysan and A. E. Lewis. New York: Russell Sage Foundation.

. 2011. "Somewhere between Jim Crow \& Post-Racialism: Reflections on the Racial Divide in America Today." Daedalus 140 (Spring): 11-36.

Bobo, Lawrence D., and Camille Z. Charles. 2009. "Race in the American Mind: From the Moynihan Report to the Obama Candidacy." Annals of the American Academy of Political and Social Science 621: 243-59.

Bobo, Lawrence D., and James R. Kluegel. 1993. "Opposition to Race-Targeting: SelfInterest, Stratification Ideology, or Racial Attitudes?" American Sociological Review 58: 443-64.

Bobo, Lawrence D., and Alicia D. Simmons. 2009 "The Race Cues, Attitudes, and Punitiveness Survey." Department of Sociology, Harvard University. Unpublished.

Bobo, Lawrence D., and Victor L. Thompson. 2010. "Racialized Mass Incarceration: Poverty, Prejudice, and Punishment." Pp. 322-55 in Doing Race: 21 Essays for the 21st Century, edited by H. R. Markus and P. M. L. Moya. New York: Norton.

Bobo, Lawrence D., James R. Kluegel, and Ryan A. Smith. 1997. "Laissez-Faire Racism: The Crystallization of a Kinder, Gentler, Antiblack Ideology." Pp. 16-42 in Racial Attitudes in the 1990s: Continuity and Change, edited by S. A. Tuch and J. K. Martin. Westport, Conn.: Praeger.

Bonacich, Edna. 1972. "A Theory of Ethnic Antagonism: The Split Labor Market." American Sociological Review 37: 447-59.

Bonilla-Silva, Eduardo. 2010. Racism without Racists: Colorblind Racism and Racial Inequality in Contemporary America. Boulder, Colo.: Rowman and Littlefield.

Brown, Michael, and David Wellman. 2005. "Embedding the Color Line: The Accumulation of Racial Advantage and Disaccumulation of Opportunity in Post-Civil Rights America." Du Bois Review 2: 187-208.

Charles, Camille Zubrinsky. 2006. Won't You Be My Neighborhood?: Race, Class and Residence in Los Angeles. New York: Russell Sage Foundation.

Chong, Dennis, and Dukhong Kim. 2006. "The Experiences and Effects of Economic Status among Racial and Ethnic Minorities." American Political Science Review 100: 335-51.

Collins, Patricia Hill. 2005. Black Sexual Politics: African Americans, Gender, and the New Racism. New York: Routledge.

Cose, Ellis. 1993. The Rage of Privileged Class. New York: Harper Collins.

Dawson, Michael C. 1994. Behind the Mule: Race and Class in African American Politics. Princeton, N.J.: Princeton University Press.

- 2001. Black Visions: The Roots of Contemporary African-American Political Ideologies. Chicago: University of Chicago Press.

De Tocqueville, Alexander. [1848] 1966. Democracy in America. New York: Harper \& Row.

Du Bois, W. E. B. [1899] 2007. The Philadelphia Negro: A Social Study. New York: Oxford University Press.

- [1903] 1999. The Souls of Black Folk. New York: Norton.
Duneier, Mitchell. 1992. Slim's Table: Race, Respectability, and Masculinity. Chicago: University of Chicago Press.

Ellison, Ralph. 1964. Shadow and Act. New York: Vintage.

Farley, Reynolds. 1996. The New American Reality: Who We Are, How We Got Here, Where We Are Going. New York: Russell Sage Foundation.

Feagin, Joe R. 200o. Racist America: Roots, Current Realities, and Future Reparations. New York: Routledge.

Feagin, Joe R., and Melvin P. Sikes. 1994. Living with Racism: The Black Middle Class Experience. Boston: Beacon Press.

Fields, Barbara J. 1982. "Ideology and Race in American History." Pp. 143-77 in Region Race, and Reconstruction: Essays in Honor of C. Vann Woodward, edited by

I. M. Kousser and J. M. McPherson. New York: Oxford University Press. . 1990. "Slavery, Race and Ideology in the United States of America." New Left Review 181: 95-118.

Franklin, John Hope. 2005. Mirror to America: The Autobiography of John Hope Franklin. New York: Farrar, Straus and Giroux.

Frazier, E. Franklin. 1957. Black Bourgeoisie: The Rise of a New Middle Class. New York: Free Press.

Fredrickson, George M. 1999. "Models of American Ethnic Relations: A Historical Perspective." Pp. 23-34 in Cultural Divides: Understanding and Overcoming Group Conflict, edited by D. A. Prentice and D. T. Miller. New York: Russell Sage Foundation.

Gaertner, Samuel L., and John F. Dovidio. 1986. “The Aversive Form of Racism.” Pp. 61-90 in Prejudice, Discrimination, and Racism, edited by J. F. Dovidio and S. L. Gaertner. New York: Academic Press.

Gans, Herbert. 1995. The War Against Poor People: The Underclass and Antipoverty Policy. New York: Basic Books.

1999. "The Possibility of a New Racial Hierarchy in the Twenty-First Century United States." Pp. 371-90 in The Cultural Territories of Race: Black and White Boundaries, edited by Michele Lamont. New York: Russell Sage Foundation.

Geronimus, Arline T., and J. Philip Thompson. 2004. "To Denigrate, Ignore, or Disrupt:

Racial Inequality in Health and the Impact of a Policy-Induced Breakdown of African American Communities." Du Bois Review 1: 247-80.

Gilens, Martin. 1999. Why Americans Hate Welfare: Race, Media, and the Politics of Antipoverty Policy. Chicago: University of Chicago Press.

Glazer, Nathan. 1971. "Blacks and Ethnic Groups: The Difference, and the Political Difference it Makes." Social Problems 18: 444-61.

- 1975. Affirmative Discrimination. New York: Basic Books.

. 1987. "The Emergence of an American Ethnic Pattern." Pp. 11-23 in From Different Shores: Perspectives on Race and Ethnicity in America, edited by R. Takaki. New York: Oxford University Press.

- 1997. We Are All Multiculturalists Now. Cambridge, Mass.: Harvard University Press.

Glenn, Evelyn Nakano. 2002. Unequal Freedom: How Race and Gender Shaped American Citizenship and Labor. Cambridge, Mass.: Harvard University Press.

Goldstone, Dwonna. 2005. "'To Exclude as Many Negro Undergraduates as Possible': Brown v. Board of Education and the University of Texas at Austin." Du Bois Review 2: 209-26.

Hacker, Andrew. 1992. Two Nations: Black and White, Separate, Hostile, Unequal. New York: Charles Scribner. 
Hammond, Linda Darling. 2004. "The Color Line in American Education: Race, Resources, and Student Achievement." Du Bois Review 1: 213-46.

Hochschild, Jennifer L. 1995. Facing Up to the American Dream: Race, Class and the Soul of the Nation. Princeton, N.J.: Princeton University Press.

Holt, Thomas C. 2000. The Problem of the Race in the 21st Century. Cambridge, Mass.: Harvard University Press.

Hsu, Hua. 2009. "The End of White America?" Atlantic 303 (January/February): 46-55.

Jackson, Walter A. 1990. Gunnar Myrdal and America's Conscience. Chapel Hill: University of North Carolina Press.

Jefferson, Thomas. [1787] 1972. Notes on the State of Virginia. New York: Norton.

Johnson, Charles. 2008. "The End of the Black American Narrative." The American Scholar 77 (Summer): $32-42$

Johnson, Guion Griffis. 1949. "The Ideology of White Supremacy, 1876-1910." Pp. 124-56 in The James Sprunt Studies in History and Political Science: Essays in Southern History, Vol. 31, edited by F. M. Green. Chapel Hill: University of North Carolina Press.

Jones, Jacqueline. 1998. "Lifework' and Its Limits: The Problem of Labor in The Philadelphia Negro." Pp. 103-26 in W. E. B. Du Bois, Race, and the City: "The Philadelphia Negro" and Its Legacy, edited by M. B. Katz and T. J. Sugrue. Philadelphia: University of Pennsylvania Press.

Katz, Irwin. 1991. "Gordon W. Allport's The Nature of Prejudice." Political Psychology 12: 125-57.

Katz, Michael B., and Thomas J. Sugrue. 1998. "Introduction: The Context of The Philadelphia Negro." Pp. 1-38 in W. E. B. Du Bois, Race, and the City: "The Philadelphia Negro" and Its Legacy, edited by M. B. Katz, and T. J. Sugrue. Philadelphia: University of Pennsylvania Press.

Kaufmann, Karen M. 2004. The Urban Voter: Group Conflict and Mayoral Voting in American Cities. Ann Arbor: University of Michigan Press.

Kinder, Donald R., and Lynn M. Sanders. 1996. Divided by Color: Racial Politics and Democratic Ideals. Chicago: University of Chicago Press.

King, Desmond S., and Rogers Smith. 2005. "Racial Orders in American Political Development." American Political Science Review 99: 75-91.

Klinkner, Philip A., and Rogers M. Smith. 1999. The Unsteady March: The Rise and Decline of Racial Equality in America. Chicago: University of Chicago Press.

Kristol, Irving. 1966. “The Negro Today Is Like the Immigrant of Yesterday." New York Times Magazine 11: 50-51, 124-42.

Lacy, Karyn. 2007. Blue Chip Black: Race, Class, and Status in the New Black Middle Class. Berkeley: University of California Press.

Landry, Bart. 1987. The New Black Middle Class. Berkeley: University of California Press.

Lieberman, Robert C. 2002. "Ideas, Institutions, and Political Order: Explaining Political Change." American Political Science Review 96: 697-712.

Lieberson, Stanley. 1980. A Piece of the Pie: Blacks and White Immigrants since 1880. Berkeley: University of California Press.

Lipset, Seymour Martin. 1960. Political Man: The Social Bases of Politics. Baltimore, Md.: Johns Hopkins University Press.

Massey, Douglas S. 2004. "Segregation and Stratification: A Biosocial Perspective." Du Bois Review 1: 7-26.

2007. Categorically Unequal: The American Stratification System. New York: Russell Sage Foundation.
Massey, Douglas S., and Nancy A. Denton. 1993. American Apartheid: Segregation and the Making of the Underclass. Cambridge, Mass.: Harvard University Press.

McDermott, Monica, and Frank L. Samson. 2005. "White Racial and Ethnic Identity in the United States." Annual Review of Sociology 31: 245-61.

Mead, Lawrence M. 1992. The New Politics of Poverty: The Nonworking Poor in America. New York: Basic Books.

Mills, Charles W. 1997. The Racial Contract. Ithaca, N.Y.: Cornell University Press. Murray, Charles A. 1984. Losing Ground: American Social Policy, 1950-1980. New York: Basic Books.

Myrdal, Gunnar. 1944. An American Dilemma: The Negro Problem and Modern Democracy New York: Random House.

Oliver, Melvin L., and Thomas M. Shapiro. 1995. Black Wealth, White Wealth: A New Perspective on Racial Inequality. New York: Routledge.

Omi, Michael A. 2001. "The Changing Meaning of Race." Pp. 243-63 in America Becoming Racial Trends and Their Consequences, Vol. 1, edited by N. J. Smelser, W. J. Wilson, and F. Mitchell. Washington, D.C.: National Academy Press.

Omi, Michael A., and Howard Winant. 1986. Racial Formation in the United States: From the 1960 s to the 1980 s. New York: Routledge.

Patterson, Orlando. 1997. The Ordeal of Integration: Progress and Resentment in America's "Racial" Crisis. Washington, D.C.: Civitas.

Pattillo, Mary. 2007. Black on the Block: The Politics of Race and Class in the City. Chicago: University of Chicago Press.

Pettigrew, Thomas F. 1998. "Intergroup Contact Theory." Annual Review of Psychology 49: $65-85$.

Sears, David O. 1988. "Symbolic Racism." Pp. 53-84 in Eliminating Racism: Profiles in Controversy, edited by P. A. Katz and D. A. Taylor. New York: Plenum.

Shelby, Tommie. 2005. We Who Are Dark: The Philosophical Foundations of Black Solidarity. Cambridge, Mass.: Harvard University Press.

Skrentny, John D. 2002. The Minority Rights Revolution. Cambridge, Mass.: Harvard University Press.

Smith, Rogers M. 1993. "Beyond Tocqueville, Myrdal, and Hartz: The Multiple Traditions in America." American Political Science Review 87: 549-66.

Smith, Sandra. 2007. Lone Pursuit: Distrust and Defensive Individualism among the Black Poor. New York: Russell Sage Foundation.

Soss, Joe, Richard Fording, and Sanford Schram. 2008. "The Color of Devolution: Race, Federalism, and the Politics of Social Control." American Journal of Political Science 52: $536-53$.

Southern, David W. 1987. Gunnar Myrdal and Black-White Relations: The Use and Abuse of an American Dilemma, 1944-1969. Baton Rouge: Louisiana State University Press.

Steedman, Marek D. 2008. "How was Race Constructed in the New South?" Du Bois Review 5: 49-67.

Stoll, Michael A. 2005. "African Americans and the Color Line." Pp. 380-413 in The American People, edited by R. Farley and J. Haaga. New York: Russell Sage Foundation.

Stone, John. 1985. Racial Conflict in Contemporary Society. Cambridge, Mass.: Harvard University Press.

Takaki, Ronald. 1970. "The Black Child-Savage in Ante-Bellum America." Pp. 27-44 in The Great Fear: Race in the Mind of America, edited by G. B. Nash. San Francisco, Calif.: Holt, Rinehart, and Winston. 
1987. "Reflections on Racial Patterns in America." Pp. 24-36 in From Different Shores: Perspectives on Race and Ethnicity in America, edited by R. Takaki. New York: Oxford University Press.

Thernstrom, Abigail, and Stephan Thernstrom. 1997. America in Black and White: One Nation, Indivisible. New York: Simon \& Schuster.

Thompson, J. Philip. 2006. Double Trouble: Black Mayors, Black Communities, and the Call for a Deep Democracy. New York: Oxford University Press.

Turner, Jonathan H., and Royce Singleton. 1978. "A Theory of Ethnic Oppression: Toward a Reintegration of Cultural and Structural Concepts in Ethnic Relations." Social Forces 56: 1001-18.

Van den Berghe, Pierre L. 1967. Race and Racism: A Comparative Perspective. New York: Wiley.

Walker, Anders. 2009. The Ghost of Jim Crow: How Southern Moderates Use Brown v. Board of Education to Stall Civil Rights. New York: Oxford University Press.

Western, Bruce. 2006. Punishment and Inequality in America. New York: Russell Sage Foundation.

Williams, David R. 1999. "Race, Socioeconomic Status, and Health: The Added Effects of Racism and Discrimination." Annals of the New York Academy of Sciences 896: 173-88.

Williams, Kim M. 2006. Mark One or More: Civil Rights in Multiracial America. Ann Arbor: University of Michigan Press.

Wilson, William Julius. 1973. Power, Racism, and Privilege: Race Relations in Theoretical and Sociohistorical Perspective. New York: MacMillan.

[1978] 1980. The Declining Significance of Race: Blacks and Changing Institutions, 2nd ed. Chicago: University of Chicago Press.

- 1987. The Truly Disadvantaged: The Inner City, the Underclass, and Public Policy. Chicago: University of Chicago Press.

- 1996. When Work Disappears: The World of the New Urban Poor. New York: Knopf. 2009. More Than Just Race: Being Black and Poor in the Inner City. New York: Norton.

Winant, Howard. 2000. "Race and Race Theory." Annual Review of Sociology 26: 169-85.

Young, Alford A. 2004. The Minds of Marginalized Black Men: Making Sense of Mobility, Opportunity, and Future Life Chances. Princeton, N.J.: Princeton University Press.

Zuberi, Tukufu. 2001. Thicker Than Blood: How Racial Statistics Lie. Minneapolis: University of Minnesota Press. 